\title{
Modeling a Helical-coil Steam Generator in RELAP5-3D for the Next Generation Nuclear Plant
}

Nathan V. Hoffer

Piyush Sabharwall

Nolan A. Anderson

January 2011

The INL is a

U.S. Department of Energy

National Laboratory

operated by

Battelle Energy Alliance

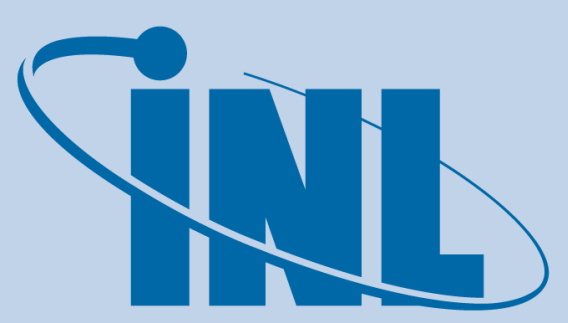

Idaho National Laboratory

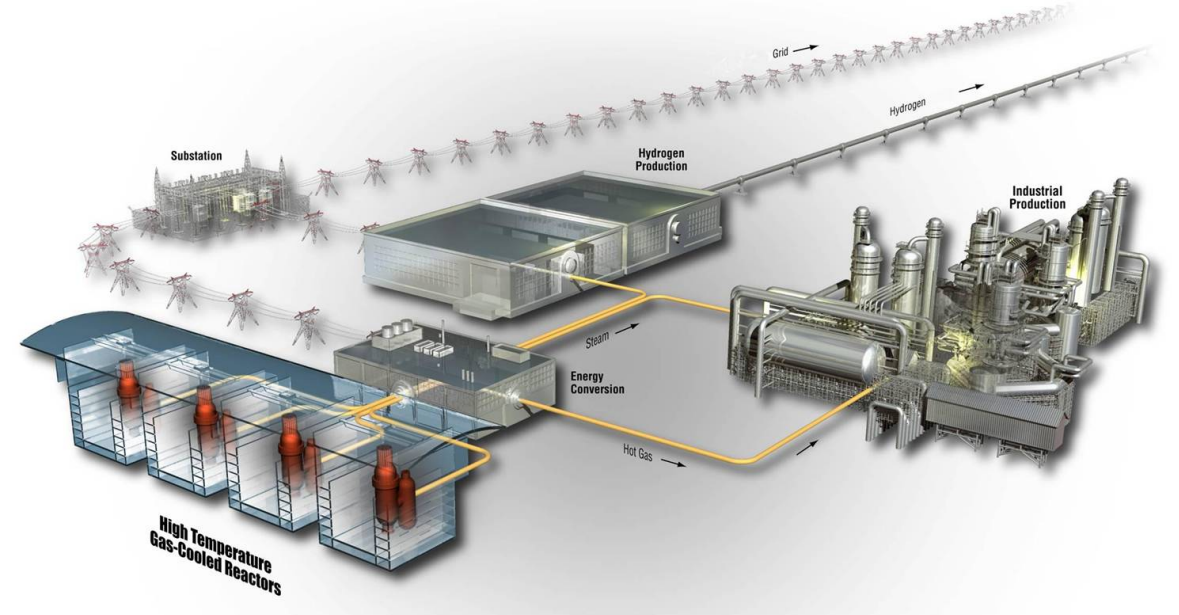




\section{DISCLAIMER}

This information was prepared as an account of work sponsored by an agency of the U.S. Government. Neither the U.S. Government nor any agency thereof, nor any of their employees, makes any warranty, expressed or implied, or assumes any legal liability or responsibility for the accuracy, completeness, or usefulness, of any information, apparatus, product, or process disclosed, or represents that its use would not infringe privately owned rights. References herein to any specific commercial product, process, or service by trade name, trade mark, manufacturer, or otherwise, does not necessarily constitute or imply its endorsement, recommendation, or favoring by the U.S. Government or any agency thereof. The views and opinions of authors expressed herein do not necessarily state or reflect those of the U.S. Government or any agency thereof. 


\title{
Modeling a Helical-coil Steam Generator in RELAP5- 3D for the Next Generation Nuclear Plant
}

\author{
Nathan V. Hoffer \\ Piyush Sabharwall \\ Nolan A. Anderson \\ January 2011 \\ Idaho National Laboratory \\ Next Generation Nuclear Plant Project \\ Idaho Falls, Idaho 83415 \\ Prepared for the \\ U.S. Department of Energy \\ Office of Nuclear Energy \\ Under DOE Idaho Operations Office \\ Contract DE-AC07-05ID14517
}



Next Generation Nuclear Plant Project

\section{Modeling a Helical-coil Steam Generator in RELAP5- 3D for the Next Generation Nuclear Plant}

INL/EXT-10-19621

January 2011

Approved by:

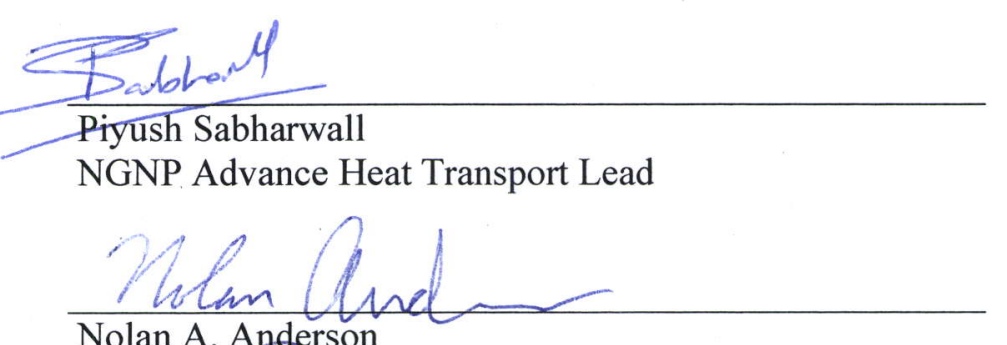

Nolan A. Anderson

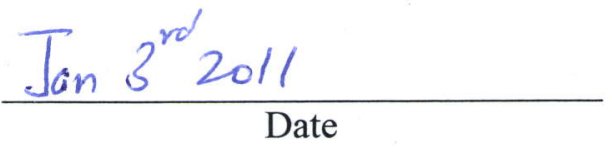

Thermal Fluids and Safety Analysis Engineer
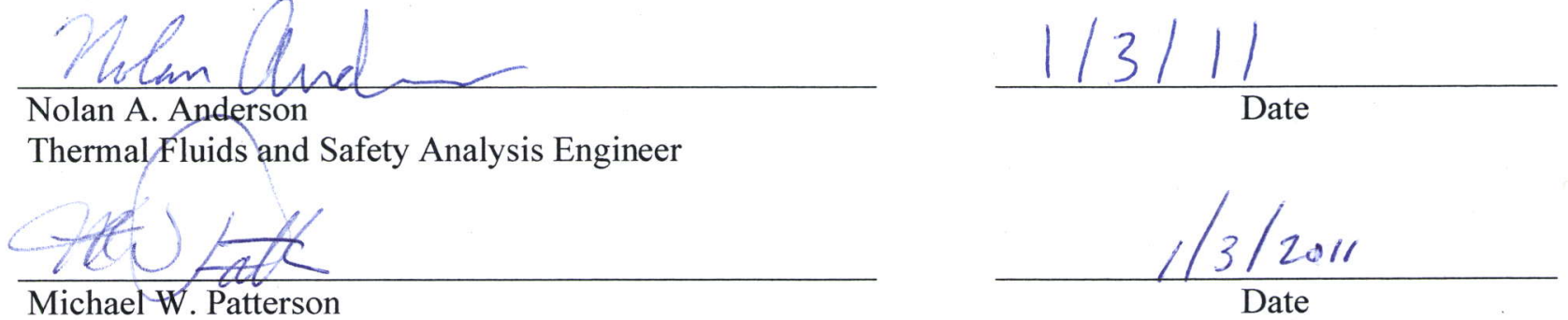

Hydrogen Process \& Heat Transport Systems

Program Manager 



\begin{abstract}
Options for the primary heat transport loop heat exchangers for the Next Generation Nuclear Plant (NGNP) are currently being evaluated. A helical-coil steam generator is one heat-exchanger design under consideration. Helical-coil steam generators are preferred over other steam generators for their increased heat transfer and compactness. Safety and reliability are an integral part of the helical-coil steam generator evaluation for NGNP. Transient analysis plays a key role in evaluating the safety of steam generators. Operational transients, such as start up, shut down, and loss of coolant accidents, are transients of interest. The helical-coil steam generator is modeled using RELAP5-3D, an Idaho National Laboratory in-house code. The transient response of an exponential loss of pressure (simulating double-ended shear) in the primary side of the steam generator is simulated. The exponential loss of pressure models a break of the steam generator inlet pipe.

This report details the development of the helical-coil steam generator model and the loss of pressure transient. Background on high temperature gas-cooled reactors and steam generators is provided to aid the reader in understanding the material presented. A detailed description of the RELAP5-3D helical-coil steam generator model is presented. An explanation is given of each of the RELAP5$3 \mathrm{D}$ components used in modeling the steam generator. Also reported is the response of the steam generator primary and secondary systems to the exponential loss of primary pressure.
\end{abstract}




\section{ACKNOWLEDGEMENTS}

The authors would like to convey special thanks to Mr. Michael W. Patterson, Mr. Cliff B. Davis, and Mr. Paul D. Bayless for their expertise, guidance, and willingness to assist with the project. 


\section{CONTENTS}

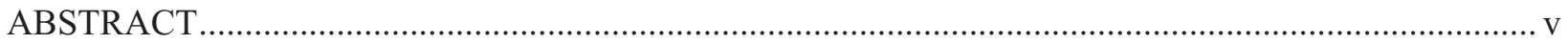

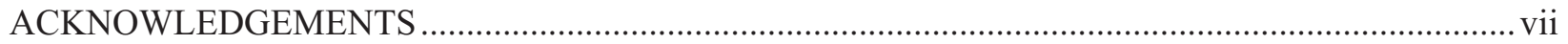

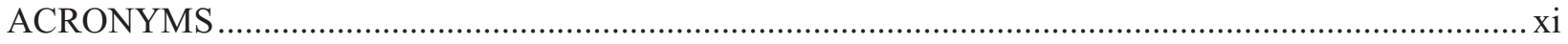

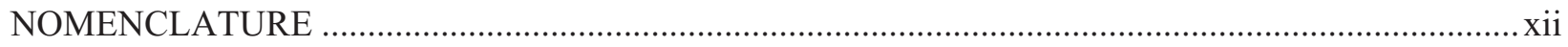

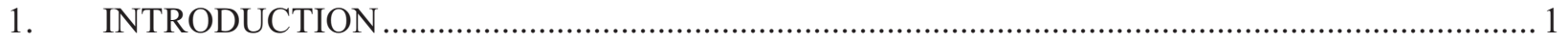

1.1 Historical Development and Background of HTGRs ...................................................... 1

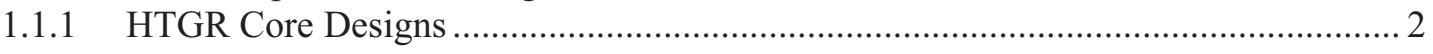

1.2 Historical Development and Background of Steam Generators .......................................... 4

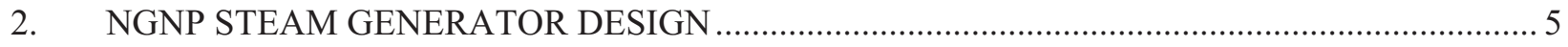

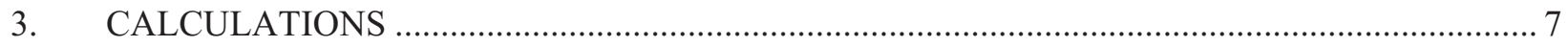

3.1 Heat Load Balance: Secondary System Initial Calculations ................................................. 7

3.2 Heat Load Balance: Secondary System Mass-Flow Rate .................................................... 9

3.3 Heat Load Balance: Primary System Mass-Flow Rate ..................................................... 11

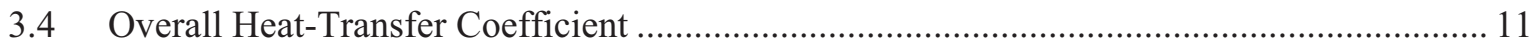

4. RELAP5-3D STEAM GENERATOR MODEL DEVELOPMENT AND DESCRIPTION ........... 12

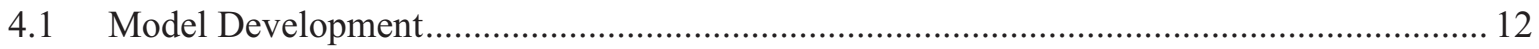

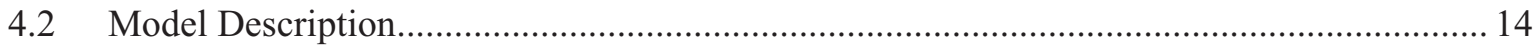

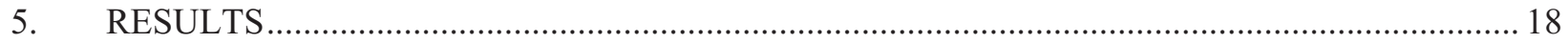

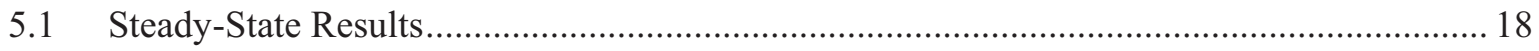

5.2 Transient Results: Exponential Decrease in Primary Pressure …....................................... 18

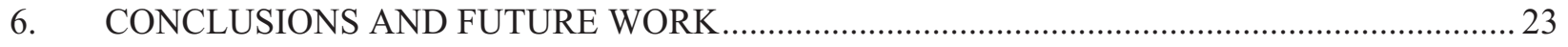

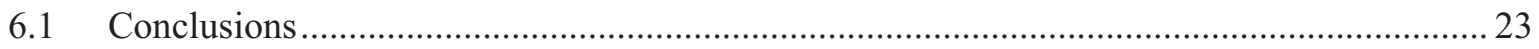

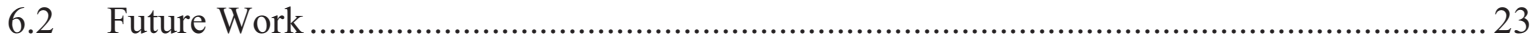

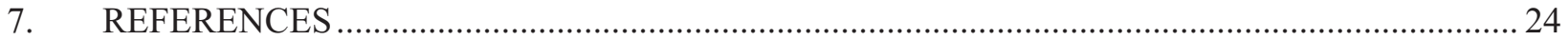

Appendix A Comparison of Heat Exchangers Reference Next Generation Nuclear Plant: Intermediate Heat Exchanger Development and Trade Studies ................................................... 25

Appendix B Transient Helical-coil Steam Generator, RELAP5-3D Input Deck .................................. 28

Appendix C Beginner's RELAP5-3D User Guide............................................................................... 49 


\section{FIGURES}

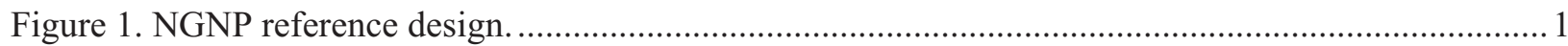

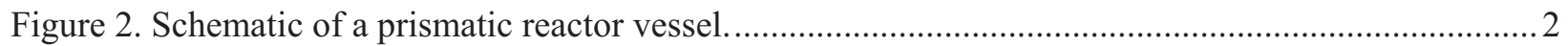

Figure 3. Schematic of the pebble-bed reactor vessel.............................................................................. 3

Figure 4. Cutaway of a helical-coil steam generator.............................................................................. 4

Figure 5. NGNP helical-coil steam-generator preconceptual design.................................................... 5

Figure 6. Calculation sections with corresponding notation. .............................................................. 7

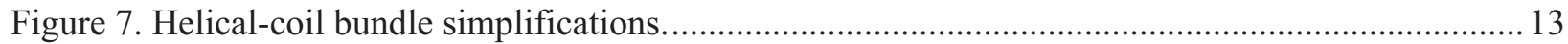

Figure 8. RELAP5-3D/ATHENA steam-generator model node visualization: primary system............... 15

Figure 9. RELAP5-3D/ATHENA steam-generator model node visualization: secondary system............. 16

Figure 10. Heat structure connections with hydrodynamic component.................................................. 17

Figure 11. Exponential pressure decrease of primary inlet pressure …..................................................... 19

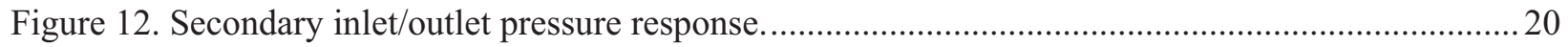

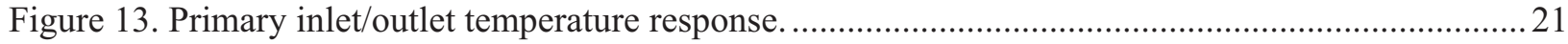

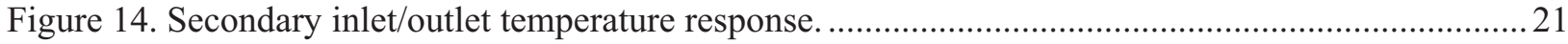

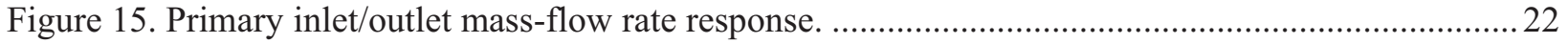

Figure 16. Secondary inlet/outlet mass-flow rate response. ….............................................................. 22

\section{TABLES}

Table 1. Preconceptual NGNP helical-coil steam generator design parameters....................................... 6

Table 2. Heat-load balance: secondary system initial conditions. ........................................................ 7

Table 3. Heat-load balance: primary system initial conditions for mass-flow rate calculations................. 11

Table 4. Conditions used in solving for the overall heat-transfer coefficient. ......................................... 11

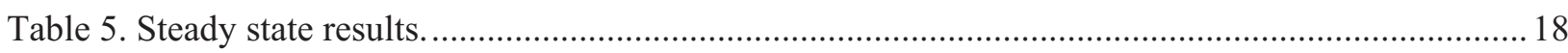

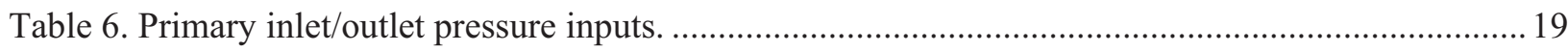

Table 7. Comparison of Heat Exchanger (Westinghouse Electric Company LLC, 2009). .....................26 


\section{ACRONYMS}

HTGR High Temperature Gas-cooled Reactor

INL Idaho National Laboratory

LOCA loss of coolant accident

LMTD log mean temperature difference

NGNP Next Generation Nuclear Plant

PWR pressurized water reactor

SG steam generator 


\section{NOMENCLATURE}

$\begin{array}{ll}C_{P} & \text { Heat capacity }[\mathrm{kJ} / \mathrm{kg} \cdot \mathrm{K}] \\ C_{P_{\text {ave }}} & \text { Average heat capacity }[\mathrm{kJ} / \mathrm{kg} \cdot \mathrm{K}] \\ d & \text { Tube diameter }[\mathrm{m}] \\ l & \text { Heated tube length }[\mathrm{m}] \\ \dot{m} & \text { Mass-flow rate }[\mathrm{kg} / \mathrm{s}] \\ N & \text { Number of tubes } \\ p & \text { Tube perimeter }[\mathrm{m}] \\ \Delta Q & \text { Difference in heat load }[\mathrm{MWt}] \\ Q & \text { Heat load }[\mathrm{MWt}] \\ S & \text { Heated surface area }\left[\mathrm{m}^{2}\right] \\ \Delta T & \text { Difference in temperature }[\mathrm{K}] \\ T & \text { Temperature }[\mathrm{K}] \\ U & \text { Overall heat transfer coefficient }\left[\mathrm{J} / \mathrm{m}^{2} \cdot \mathrm{s} \cdot \mathrm{K}\right]\end{array}$

\section{Subscripts}

inlet Inlet of primary or secondary system of steam generator

LMTD Log mean temperature difference

o Tube outer dimension

\section{RELAP5-3D Coding}

ANNULUS Annulus component: used to model an annulus

PIPE Pipe component: used to model pipe or tubes

SNGLJUN Single junction component: a hydrodynamic component used to join other hydrodynamic components together, model abrupt area changes, and pressure loss coefficients.

TMDPJUN Time dependent junction component: controls the mass-flow rate

TMDPVOL Time dependent volume component: controls the temperature and pressure and acts as a source or sink 


\section{Modeling a Helical-coil Steam Generator in RELAP5- 3D for the Next Generation Nuclear Plant}

\section{INTRODUCTION}

With the recent advances in nuclear technologies, the possibility of using nuclear plants for process heat production is closer than ever before. The Next Generation Nuclear Plant (NGNP), a high temperature gas-cooled reactor (HTGR) design, is based on providing process heat to a wide range of high temperature processes. NGNP will be able to provide electrical power and process heat to be used in hydrogen production, industrial applications, coal gasification, enhanced oil recovery (Sabharwall, 2009), and several other petro-chemical processes. Safety and reliability are paramount to the success of the NGNP. A key component of the NGNP reference design is the steam generator (SG) as shown in Figure 1 (NGNP Senior Advisory Group, 2009). Analysis of the steam generator under operational as well as transient conditions is an integral part of the safety and reliability of the NGNP (Munshi et al. 1986). To analyze transients in the steam generator, it is necessary to develop accurate models. RELAP5-3D is an industry-accepted code that provides a platform for steam generator two-phase flow transient analysis.

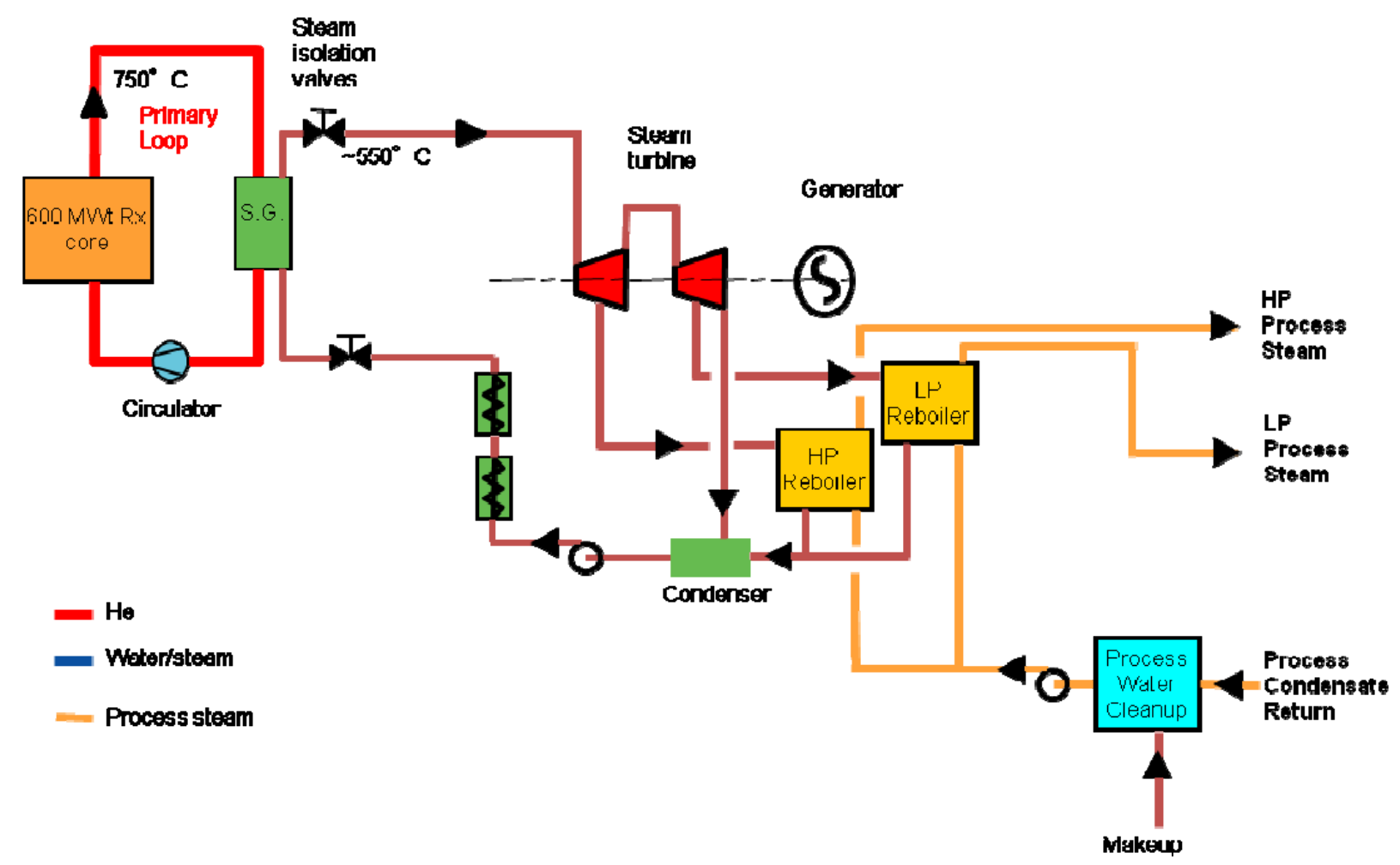

Figure 1. NGNP reference design.

\subsection{Historical Development and Background of HTGRs}

Since the inception of nuclear power there have been several advances in nuclear power plant design, especially with regard to reactor core design. Several different designs are being considered for the next generation of nuclear power plants. One such design is the HTGR concept, which has the goal of providing high temperature process heat (General Atomics, 2009). 
HTGRs use helium as the coolant because of its non-reactivity at high temperatures. The inert nature of helium is also beneficial to the reactor core structure as well as to the steam generator where other coolants corrode the structure at high temperatures (Melese and Katz, 1984). Also, as helium passes through the core, it does not become radioactive, which provides added safety in the event of a breach in the reactor.

\subsubsection{HTGR Core Designs}

There are two distinct core designs for HTGRs: prismatic and pebble bed.

\subsubsection{Prismatic Core Design}

The prismatic core is made up of an outer core barrel, permanent and replaceable side reflectors, annular core, and a replaceable central reflector, as shown in Figure 2. The annular core consists of hexagonal graphite blocks stacked on top of each other. Each graphite block contains cylindrical holes. Helium coolant passes through these holes, which also house cylindrical fuel compacts and control rods.

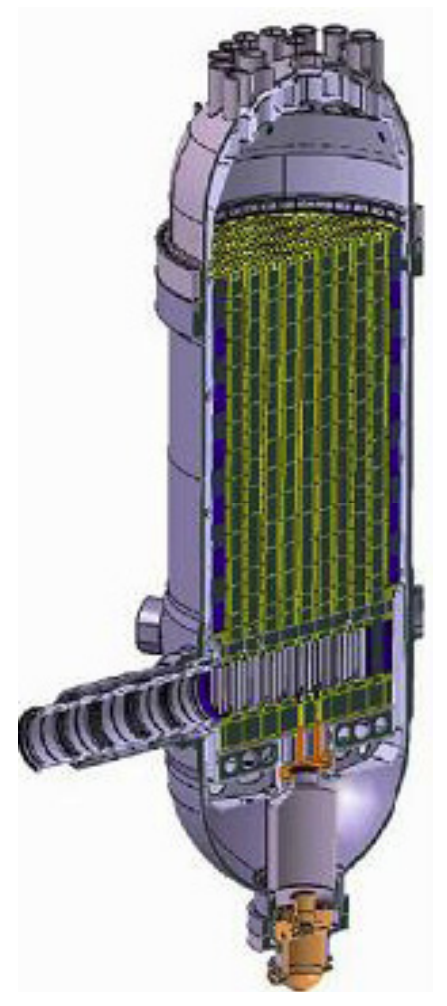

Figure 2. Schematic of a prismatic reactor vessel.

\subsubsection{Pebble-Bed Core Design}

The main characteristic of a pebble-bed reactor is its fuel form. As with a prismatic core, the pebble bed core has a core barrel with side reflectors, a central reflector, an annulus for fuel, and helium for coolant. Unlike the prismatic core hexagonal fuel elements, the pebble bed uses billiard-ball-sized spheres packed with fuel particles suspended in a graphite matrix. The spheres slowly flow down through the annular section of the core and are then cycled back into the core. The annular geometry of the pebble bed core provides the same benefits with regard to heat transfer and passive safety. A cross section of a pebble-bed reactor is shown in Figure 3 (Idaho National Laboratory, May 2009). 


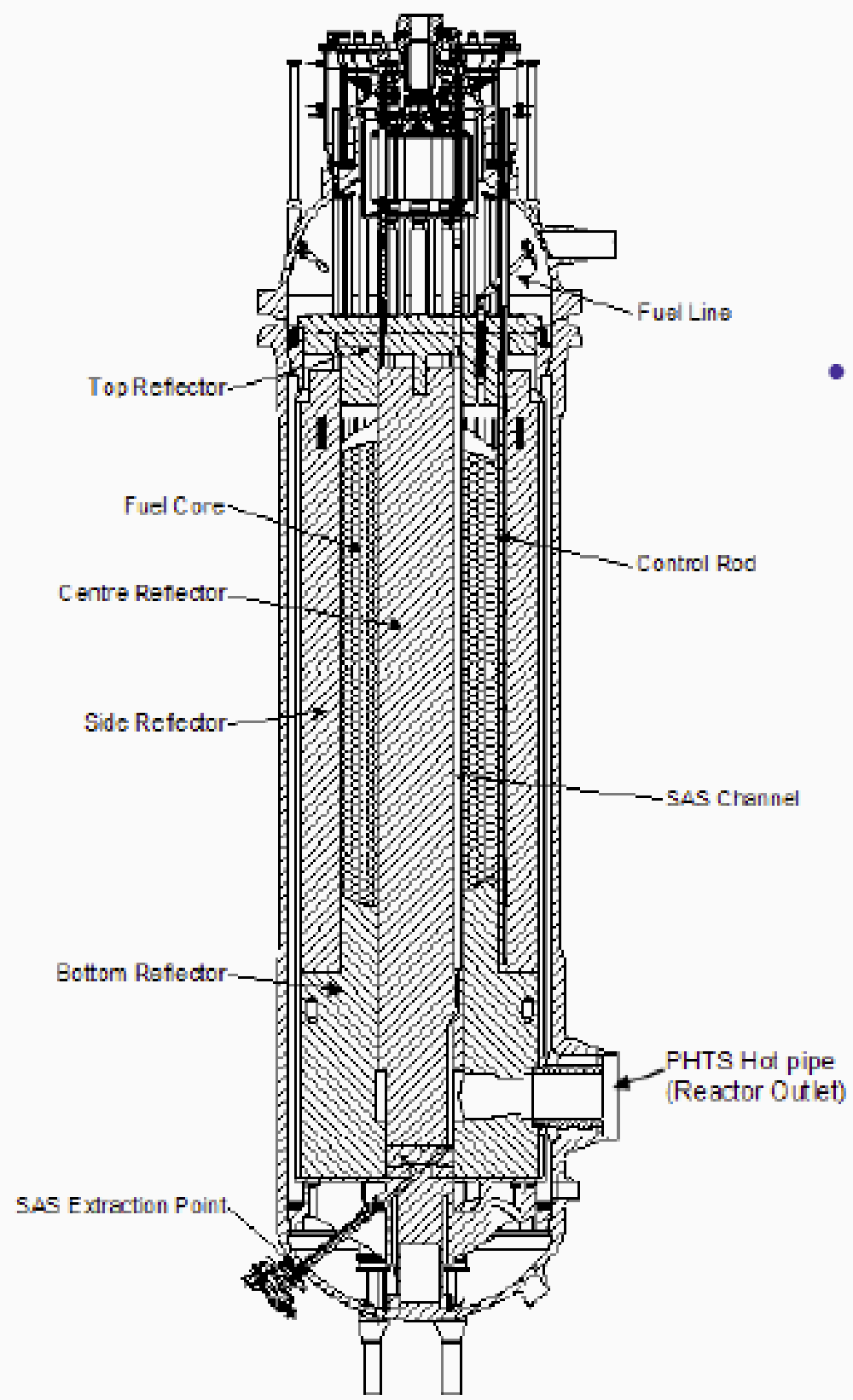

Figure 3. Schematic of the pebble-bed reactor vessel. 


\subsection{Historical Development and Background of Steam Generators}

A steam generator is a heat exchanger made up of a shell (primary side) and several small tubes (secondary side), on the order of centimeters in diameter, which are bundled together. There are several shell and tube configurations. To increase heat transfer, baffles can be used to force the shell side coolant to cross over the tubes. Baffle designs vary widely, but serve the same purpose to increase the effectiveness of the heat exchanger. Tubes can also make more than one pass through the shell to increase the heat exchanger effectiveness. The tubes can be modified to have fins that increase heat transfer area.

Steam generators typically transfer heat from the shell side coolant to the tube side coolant, producing steam within the tubes. However, in PWRs, lower-pressure steam is produced on the shell side, and the high-pressure reactor coolant is circulated through the tubes. This design minimizes the shell wall thickness, but also makes the shell susceptible to corrosion (Melese and Katz, 1984). An advance in steam-generator design is the helical-coil design which offers compactness and increased heat transfer (Prabhanjan, et al., 2002). The tubes of the steam generator are wound into helical coils, forming a large bundle as shown in the Figure 4 (Areva, 2008). Helical-coil heat exchangers can have a 16 to $43 \%$ higher heat transfer coefficient than straight pipe heat exchangers (Prabhanjan, et al., 2002). Several issues still exist related to steam generators in nuclear power plants. For example, fouling and plugging of tubes is a major concern because it decreases the efficiency of the steam generator and requires a complete plant shutdown for servicing. Steam generators are also at risk of bursting tubes, which causes the mixing of the primary and secondary fluids, disrupting reactor conditions (Electric Power Research Institute, 1994).

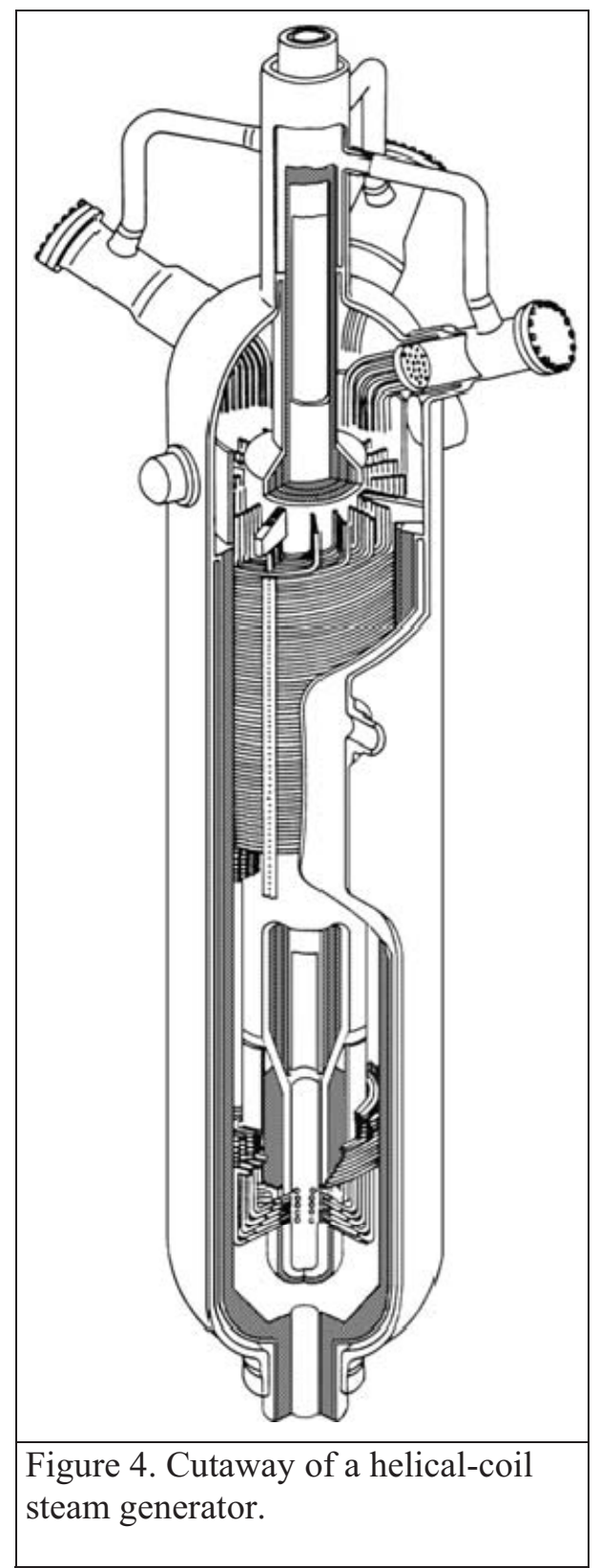




\section{NGNP STEAM GENERATOR DESIGN}

The NGNP project is evaluating several different heat exchangers as candidates for the primary heat transport system. The primary heat transport system consists of the reactor, heat exchanger, and powerproduction system. The helical-coil steam generator design is currently at the forefront of these heat exchangers. The NGNP design is based on a modular HTGR (MHTGR) steam-generator design. The steam-generator reference design is a vertically oriented, once-through, up-boiling, cross-counter-flow, shell and tube heat exchanger (Idaho National Laboratory, August 2009), shown in Figure 5. The multiple tubes are helically wound into bundles. The NGNP design has an upper bundle and lower bundle. The upper bundle experiences very high temperatures $\left(\sim 750^{\circ} \mathrm{C}\right)$ which require high temperature alloys like Inconel 617 and Incoloy 800H (General Atomics, 2008). These alloys have high corrosion resistance and structural strength at high temperatures. The upper and lower bundles are joined by a bimetallic weld. The lower bundle experiences lower temperatures and is made of a lower temperature alloy $2-1 / 4 \mathrm{Cr}-1 \mathrm{Mo}$. The lower bundle can be divided into three sections. The first section can be thought of as an economizer that preheats the feedwater. The second section can be thought of as an evaporator that converts water into steam. The last section of the lower bundle represents the initial superheater that converts left-over liquid water into steam. The upper bundle acts as the finishing superheater that completely converts saturated steam into dry steam to prevent damage to the turbine.

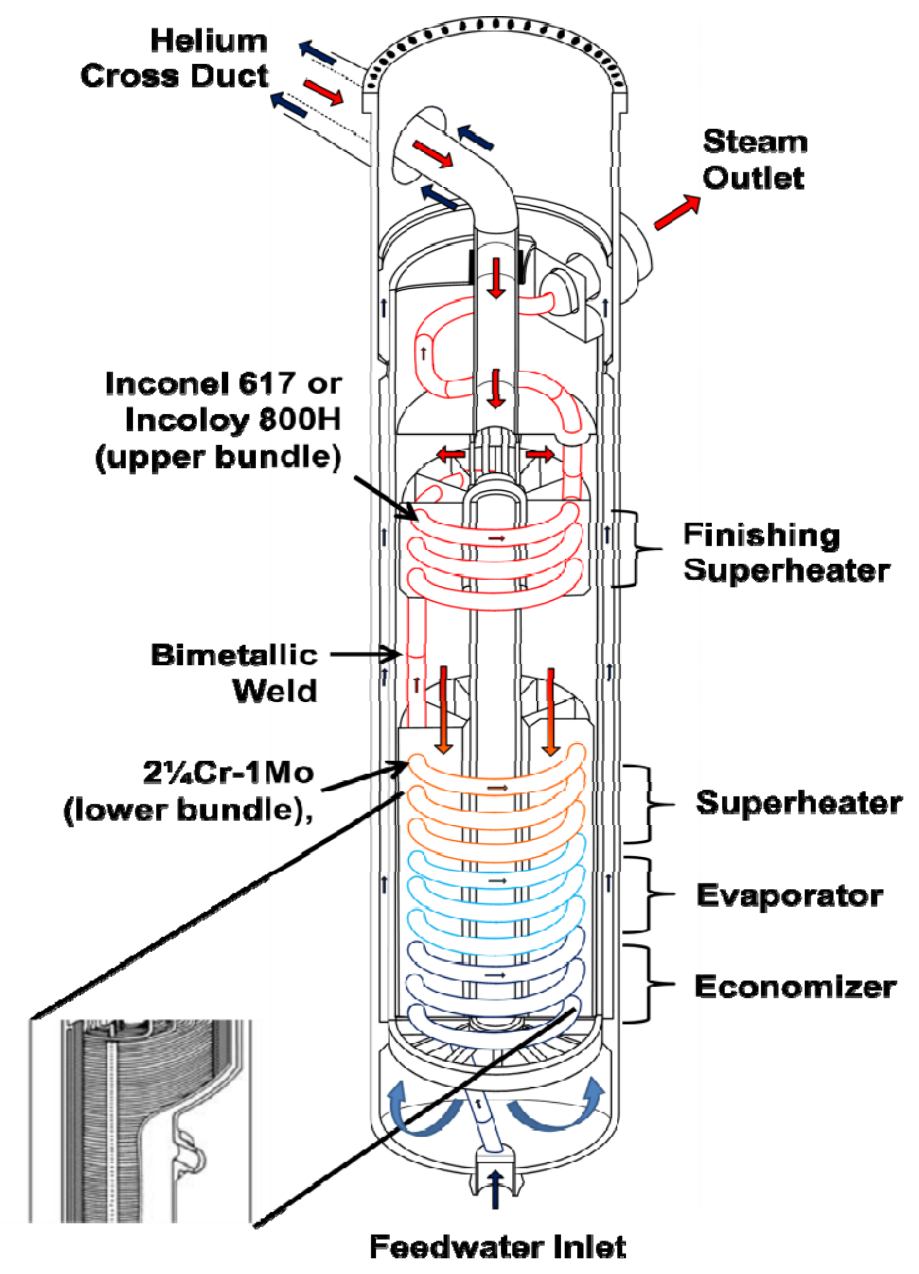

Figure 5. NGNP helical-coil steam-generator preconceptual design. 
Helium enters the steam generator through the cross duct and is directed down through a central pipe. The central pipe opens up into an inner plenum. The helium then flows down around the individual helical-coil tubes. At the base plenum, the helium is redirected up through the annulus between the outer and inner shrouds, combining into the upper plenum. The helium then exits out the cross duct back into the reactor.

On the shell side, liquid water enters through the feedwater inlet and passes through the economizer, evaporator, and superheater sections, producing steam. The steam continues to the finishing superheater, which converts all steam into dry steam, before entering the turbomachinery.

The design parameters for the NGNP helical-coil steam generator (General Atomics, 2008; General Atomics, 2009) are shown in Table 1.

Table 1. Preconceptual NGNP helical-coil steam generator design parameters.

\begin{tabular}{|l|c|}
\hline \multicolumn{1}{|c|}{ Parameter } & NGNP Value \\
\hline Heat Load, MWt & 600 \\
\hline Primary Inlet Temperature, ${ }^{\circ} \mathrm{C}$ & 750 \\
\hline Primary Outlet Temperature, ${ }^{\circ} \mathrm{C}$ & 322 \\
\hline Primary Mass-Flow Rate, $\mathrm{kg} / \mathrm{s}$ & 250 \\
\hline Primary Inlet Pressure, $\mathrm{MPa}$ & 7.0 \\
\hline Primary Outlet Pressure, $\mathrm{MPa}$ & 6.976 \\
\hline Secondary Inlet Temperature, ${ }^{\circ} \mathrm{C}$ & 200 \\
\hline Secondary Outlet Temperature, ${ }^{\circ} \mathrm{C}$ & 540 \\
\hline Secondary Mass-Flow Rate, $\mathrm{kg} / \mathrm{s}$ & 216 \\
\hline Secondary Inlet Pressure, $\mathrm{MPa}$ & 18.2 \\
\hline Secondary Outlet Pressure, $\mathrm{MPa}$ & 17.2 \\
\hline Number of Tubes & 441 \\
\hline
\end{tabular}




\section{CALCULATIONS}

A heat-load balance was performed as the basis for the steady-state RELAP5 steam-generator model. The steam generator's secondary side was split into three sections, as shown in Figure 6. The lower section (points marked Tin to T4) consists of the feedwater inlet to the point at which water begins to vaporize at the inlet pressure. The next section (points marked T4 to T5) lies between the water vaporization point and the bimetallic weld (point marked T5), being the separation point of the two different tube materials; within this section, the secondary fluid is a two-phase fluid. The third section (points marked T5 to T6) consists of the portion above the bimetallic weld to the steam outlet. This section is assumed to be completely steam. It is assumed that the value of the specific heat, $C_{P}$ can be averaged between temperature points. Table 2 shows the initial conditions that were used in calculating the heat load balance for the secondary system.

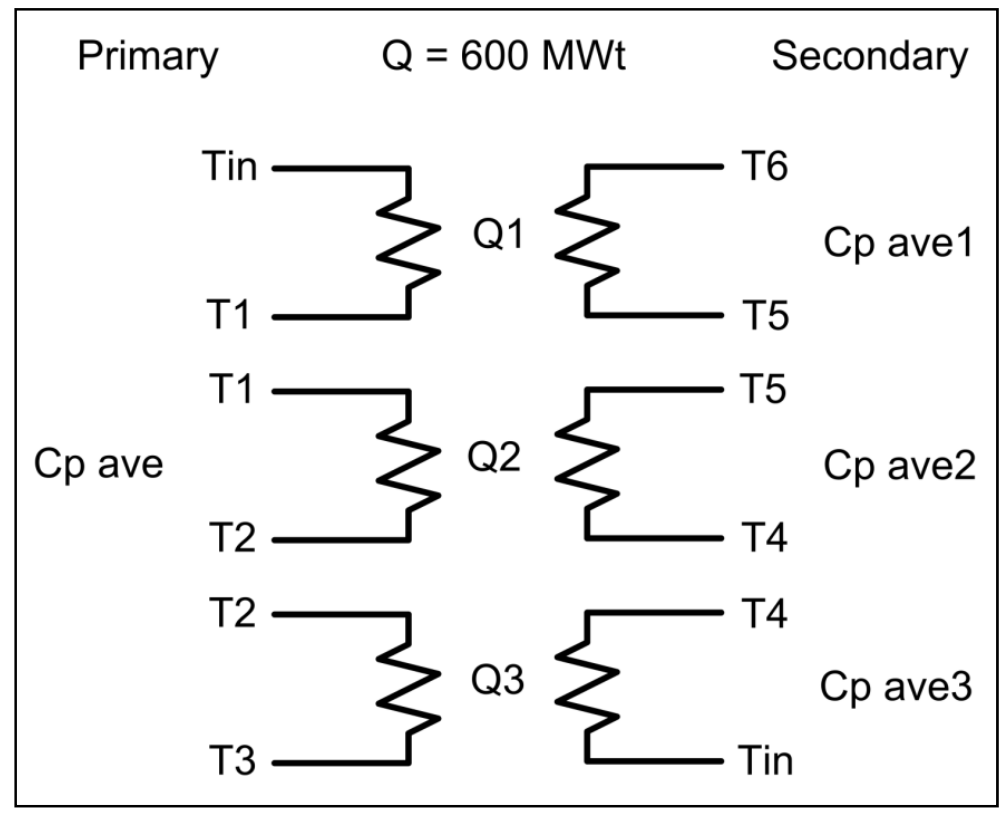

Figure 6. Calculation sections with corresponding notation.

\subsection{Heat Load Balance: Secondary System Initial Calculations}

Table 2. Heat-load balance: secondary system initial conditions.

\begin{tabular}{|l|c|}
\hline \multicolumn{1}{|c|}{ Parameter } & Value \\
\hline Heat Load, MWt & 600 \\
\hline Secondary inlet temperature, ${ }^{\circ} \mathrm{C}\left({ }^{\circ} \mathrm{F}\right)$ & $200(392)$ \\
\hline Secondary inlet pressure, $\mathrm{MPa}(\mathrm{psi})$ & $18.2(2640)$ \\
\hline $\mathrm{H}_{2} \mathrm{O}$ phase change temperature, ${ }^{\circ} \mathrm{C}\left({ }^{\circ} \mathrm{F}\right)$ & $358(676.4)$ \\
\hline Secondary mass-flow rate, $\mathrm{kg} / \mathrm{s}(\mathrm{lbm} / \mathrm{s})$ & $216(476.2)$ \\
\hline
\end{tabular}


Solving for heat load from inlet to $\mathrm{H}_{2} \mathrm{O}$ phase change of the secondary side.

1. Calculate average heat capacity:

$$
\begin{aligned}
& C_{P_{\text {inlet }}}=4.4085 \frac{\mathrm{kJ}}{\mathrm{kg} \cdot{ }^{\circ} \mathrm{C}} \\
& C_{P_{4 \text { liquid }}}=13.467 \frac{\mathrm{kJ}}{\mathrm{kg} \cdot{ }^{\circ} \mathrm{C}} \\
& C_{P_{\text {ave } 3}}=\frac{C_{P_{4 \text { liquid }}}+C_{P_{\text {inlet }}}}{2}=8.935 \frac{\mathrm{kJ}}{\mathrm{kg} \cdot{ }^{\circ} \mathrm{C}}
\end{aligned}
$$

2. Calculate the temperature difference:

$$
\Delta T_{3}=T_{4}-T_{\text {inlet }}=158^{\circ} \mathrm{C}
$$

3. Calculate heat load:

$$
Q_{3}=\dot{m} * C_{P_{\text {ave } 3}} * \Delta T_{3}=304.925 \mathrm{MW}
$$
side:

Solving for the heat load form the $\mathrm{H}_{2} \mathrm{O}$ phase change to the change in tube material of the secondary

1. Assume that the fluid temperature at the point where the material change occurs is $450^{\circ} \mathrm{C}$.

$$
T_{5}=450^{\circ} \mathrm{C}
$$

2. Calculate average heat capacity:

$$
\begin{aligned}
& C_{P_{4 \text { vapor }}}=24.265 \frac{\mathrm{kJ}}{\mathrm{kg} \cdot{ }^{\circ} \mathrm{C}} \\
& C_{P_{5}}=3.709 \frac{\mathrm{kJ}}{\mathrm{kg} \cdot{ }^{\circ} \mathrm{C}} \\
& C_{P_{\text {ave } 2}}=\frac{C_{P_{4} \text { vapor }}+C_{P_{5}}}{2}=13.867 \frac{\mathrm{kJ}}{\mathrm{kg} \cdot{ }^{\circ} \mathrm{C}}
\end{aligned}
$$

3. Calculate temperature difference:

$$
\Delta T_{2}=T_{5}-T_{4}=92^{\circ} \mathrm{C}
$$

4. Calculate heat load:

$$
Q_{2}=\dot{m} * C_{P_{\text {ave } 2}} * \Delta T_{2}=275.575 \mathrm{MW}
$$

5. Calculate heat load difference between total heat load and $\mathrm{Q}_{3}$ :

$$
\Delta Q=Q-Q_{3}=295.075 \mathrm{MW}
$$

Solve for the heat load from the change in tube material to the steam outlet.

$$
Q_{1}=\Delta Q-Q_{2}=19.5 \mathrm{MW}
$$

Solving for the secondary outlet temperature:

1. Assume an outlet temperature of $540^{\circ} \mathrm{C}$ for outlet heat capacity. 
2. Calculate average heat capacity:

$$
\begin{aligned}
& C_{P_{6}}=2.9045 \frac{\mathrm{kJ}}{\mathrm{kg} \cdot{ }^{\circ} \mathrm{C}} \\
& C_{P_{5}}=3.709 \frac{\mathrm{kJ}}{\mathrm{kg} \cdot{ }^{\circ} \mathrm{C}} \\
& C_{P_{\text {ave } 1}}=\frac{C_{P_{6}}+C_{P_{5}}}{2}=3.306 \frac{\mathrm{kJ}}{\mathrm{kg} \cdot{ }^{\circ} \mathrm{C}}
\end{aligned}
$$

3. Calculate outlet temperature:

$$
T_{6}=T_{5}+\frac{Q_{1}}{\dot{m} * C_{P_{\text {ave } 1}}}=477.31^{\circ} \mathrm{C} .
$$

The outlet temperature is significantly lower than the design temperature of $540^{\circ} \mathrm{C}$. Since the heat capacity and the heat load are assumed to be parameters, the secondary mass-flow rate must be adjusted to achieve the desired steam outlet temperature.

\subsection{Heat Load Balance: Secondary System Mass-Flow Rate}

The secondary mass-flow rate was solved for iteratively by assuming a heat load for the section containing the secondary inlet to the temperature at which $\mathrm{H}_{2} \mathrm{O}$ changes phase for a pressure of $18.2 \mathrm{MPa}$. The heat load choice was checked against the steam outlet temperature until it coincided with the design steam outlet temperature of $540^{\circ} \mathrm{C}$.

Solving for mass-flow rate of the secondary side:

1. Assume a heat load of 346.3 MW from the inlet to the phase change section. This heat load value is an iterative estimation which is then used to determine the mass-flow rate necessary to obtain an outlet temperature of $540{ }^{\circ} \mathrm{C}$.

$$
Q_{3}=346.3 \mathrm{MW}
$$

2. Calculate average heat capacity:

$$
\begin{aligned}
& C_{P_{\text {inlet }}}=4.4085 \frac{\mathrm{kJ}}{\mathrm{kg} \cdot{ }^{\circ} \mathrm{C}} \\
& C_{P_{4 \text { liquid }}}=13.467 \frac{\mathrm{kJ}}{\mathrm{kg} \cdot{ }^{\circ} \mathrm{C}} \\
& C_{P_{\text {ave } 3}}=\frac{C_{P_{4 \text { liquid }}}+C_{P_{\text {inlet }}}}{2}=8.935 \frac{\mathrm{kJ}}{\mathrm{kg} \cdot{ }^{\circ} \mathrm{C}}
\end{aligned}
$$

3. Calculate the temperature difference:

$$
\Delta T_{3}=T_{4}-T_{\text {inlet }}=158^{\circ} \mathrm{C}
$$

4. Calculate secondary mass-flow rate:

$$
\dot{m}=\frac{Q_{3}}{C_{P_{\text {ave } 3}} * \Delta T_{3}}=245.309 \frac{\mathrm{kg}}{\mathrm{s}}
$$


Solving for the heat load from the $\mathrm{H}_{2} \mathrm{O}$ phase change to the change in tube material of the secondary side.

1. Assume material change occurs at a fluid temperature of $450^{\circ} \mathrm{C}$.

$$
T_{5}=450^{\circ} \mathrm{C}
$$

2. Calculate heat load difference between total heat load and $Q_{3}$.

$$
\Delta Q=Q-Q_{3}=253.70 \mathrm{MW}
$$

3. Calculate average heat capacity:

$$
\begin{aligned}
& C_{P_{4 \text { vapor }}}=12.504 \frac{\mathrm{kJ}}{\mathrm{kg} \cdot{ }^{\circ} \mathrm{C}} \\
& C_{P_{5}}=3.560 \frac{\mathrm{kJ}}{\mathrm{kg} \cdot{ }^{\circ} \mathrm{C}} \\
& C_{P_{\text {ave } 2}}=\frac{C_{P_{4} \text { vapor }}+C_{P_{5}}}{2}=8.035 \frac{\mathrm{kJ}}{\mathrm{kg} \cdot{ }^{\circ} \mathrm{C}}
\end{aligned}
$$

4. Calculate temperature difference:

$$
\Delta T_{2}=T_{5}-T_{4}=92^{\circ} \mathrm{C}
$$

5. Calculate heat load:

$$
Q_{2}=\dot{m} * C_{P_{\text {ave } 2}} * \Delta T_{2}=181.271 M W
$$

Solve for the heat load from the change in tube material to the steam outlet.

$$
Q_{1}=\Delta Q-Q_{2}=72.429 \mathrm{MW}
$$

Solving for the secondary outlet temperature:

1. Assume an outlet temperature of $540^{\circ} \mathrm{C}$ at $17.2 \mathrm{MPa}$ for outlet heat capacity.

2. Calculate average heat capacity:

$$
\begin{aligned}
& C_{P_{6}}=2.8492 \frac{\mathrm{kJ}}{\mathrm{kg} \cdot{ }^{\circ} \mathrm{C}} \\
& C_{P_{5}}=3.709 \frac{\mathrm{kJ}}{\mathrm{kg} \cdot{ }^{\circ} \mathrm{C}} \\
& C_{P_{\text {ave } 1}}=\frac{C_{P_{6}}+C_{P_{5}}}{2}=3.279 \frac{\mathrm{kJ}}{\mathrm{kg} \cdot{ }^{\circ} \mathrm{C}}
\end{aligned}
$$

Calculate steam outlet temperature:

$$
T_{6}=T_{5}+\frac{Q_{1}}{\dot{m} * C_{P_{\text {ave } 1}}}=540.04^{\circ} \mathrm{C}
$$

The calculated temperature now coincides with the design temperature of $540^{\circ} \mathrm{C}$. The secondary mass-flow rate was adjusted from 216 to $245.31 \mathrm{~kg} / \mathrm{s}$. 


\subsection{Heat Load Balance: Primary System Mass-Flow Rate}

The primary system coolant is helium, which has little variation in heat capacity over large temperature ranges. Because of this characteristic, the primary system mass-flow rate is solved without dividing the system into three sections. The section temperatures will however be calculated. Table 3 shows the initial conditions that were used in calculating the primary system mass-flow rate.

Table 3. Heat-load balance: primary system initial conditions for mass-flow rate calculations.

\begin{tabular}{|l|c|}
\hline \multicolumn{1}{|c|}{ Parameter } & Value \\
\hline Heat Load, MWt & 600 \\
\hline Primary Inlet Temperature, ${ }^{\circ} \mathrm{C}\left({ }^{\circ} \mathrm{F}\right)$ & $750(1382)$ \\
\hline Primary Outlet Temperature, ${ }^{\circ} \mathrm{C}\left({ }^{\circ} \mathrm{F}\right)$ & $322(611.6)$ \\
\hline Primary Inlet Pressure, $\mathrm{MPa}(\mathrm{psi})$ & $7.0(1020)$ \\
\hline
\end{tabular}

Solving for mass-flow rate of the secondary side:

1. Calculate average heat capacity:

$$
\begin{aligned}
& C_{P_{\text {inlet }}}=5.1898 \frac{\mathrm{kJ}}{\mathrm{kg} \cdot{ }^{\circ} \mathrm{C}} \\
& C_{P_{3}}=5.1879 \frac{\mathrm{kJ}}{\mathrm{kg} \cdot{ }^{\circ} \mathrm{C}} \\
& C_{P_{\text {ave }}}=\frac{C_{P_{3}}+C_{P_{\text {inlet }}}}{2}=5.189 \frac{\mathrm{kJ}}{\mathrm{kg} \cdot{ }^{\circ} \mathrm{C}}
\end{aligned}
$$

2. Calculate the temperature difference:

$$
\Delta T=T_{\text {in }}-T_{3}=428^{\circ} \mathrm{C}
$$

3. Calculate primary mass-flow rate:

$$
\dot{m}=\frac{Q}{C_{P_{\text {ave }}} * \Delta T}=270.17 \frac{\mathrm{kg}}{\mathrm{s}}
$$

The calculated primary outlet temperature matches the design temperatures. The primary mass-flow rate was adjusted from 250 to $270.17 \mathrm{~kg} / \mathrm{s}$ so that the design outlet temperature could be obtained.

\subsection{Overall Heat-Transfer Coefficient}

Table 4 shows the conditions that were used in solving for the overall heat transfer coefficient.

Table 4. Conditions used in solving for the overall heat-transfer coefficient.

\begin{tabular}{|l|c|}
\hline \multicolumn{1}{|c|}{ Parameter } & Value \\
\hline Heat Load, MWt & 600 \\
\hline Number of Tubes & 441 \\
\hline Tube Outer Diameter, $\mathrm{m}(\mathrm{ft})$ & $0.0318(0.104)$ \\
\hline Assumed Single Heated Tube Length, $\mathrm{m}(\mathrm{ft})$ & $144(472.4)$ \\
\hline Primary Inlet Temperature, ${ }^{\circ} \mathrm{C}\left({ }^{\circ} \mathrm{F}\right)$ & $750(1382)$ \\
\hline
\end{tabular}




\begin{tabular}{|l|c|}
\hline Primary Outlet Temperature, ${ }^{\circ} \mathrm{C}\left({ }^{\circ} \mathrm{F}\right)$ & $322(611.6)$ \\
\hline Secondary Inlet Temperature, ${ }^{\circ} \mathrm{C}\left({ }^{\circ} \mathrm{F}\right)$ & $200(392)$ \\
\hline Secondary Outlet Temperature,${ }^{\circ} \mathrm{C}\left({ }^{\circ} \mathrm{F}\right)$ & $540(1004)$ \\
\hline
\end{tabular}

Solving for the overall heat transfer coefficient

$$
\begin{aligned}
& N=441 \text { tubes } \\
& l=144 \mathrm{~m}
\end{aligned}
$$

1. Calculate single tube perimeter:

$$
p=2 * \pi * \frac{d_{o}}{2}=0.099 m
$$

2. Calculated heated surface area:

$$
S=N * p * l=5022.51 \mathrm{~m}^{2}
$$

3. Calculate the log mean temperature difference:

$$
\begin{aligned}
& T_{1}=750^{\circ} \mathrm{C} \\
& T_{2}=322^{\circ} \mathrm{C} \\
& T_{3}=200^{\circ} \mathrm{C} \\
& T_{4}=540^{\circ} \mathrm{C} \\
& \Delta T_{L M T D}=\frac{\left(T_{1}-T_{4}\right)-\left(T_{2}-T_{3}\right)}{\ln \left(\frac{T_{1}-T_{4}}{T_{2}-T_{3}}\right)}=162.04^{\circ} \mathrm{C}
\end{aligned}
$$

4. Calculate the overall heat transfer coefficient

$$
U=\frac{Q}{S * \Delta T_{L M T D}}=737.25 \frac{\mathrm{J}}{\mathrm{m}^{2} \cdot \mathrm{s} \cdot{ }^{\circ} \mathrm{C}}
$$

\section{RELAP5-3D STEAM GENERATOR MODEL DEVELOPMENT AND DESCRIPTION}

\subsection{Model Development}

Since the NGNP helical-coil steam generator is still being developed, several steam generators were referenced for flow path and dimensions. Flow path was based on an MHTGR steam generator (MHTGR, circa 1987). Dimensions and inlet and outlet conditions were referenced from other reports (Westinghouse Electric Company, LLC, 2009, General Atomics 2008, General Atomics 2009, Oh et al. 2010).

RELAP5-3D software was used to develop a computer model of the steam generator. RELAP5 is an Idaho National Laboratory in-house code used to simulate operational transients and loss of coolant accidents (LOCAs) within a nuclear power plant. Modeling a three-dimensional helical-coil bundle in 
RELAP5 required several simplifications, as show in Figure 7. First the helical-coil bundle of 441 tubes was modeled as a single tube with equivalent flow area, heat transfer surface area, hydraulic diameter, and heated hydraulic diameter. Equivalent areas and diameters of the single tube estimate the heattransfer and flow characteristics of the actual bundle of tubes. The single tube helical coil was further simplified by unwrapping the coil tube to make an inclined straight pipe of the same length as a single tube and a vertical change in elevation corresponding to the bundle height. A heat transfer multiplier was added to the model to simulate improved heat transfer as observed in helical coils. With these simplifications, the helical-coil steam-generator model was developed.

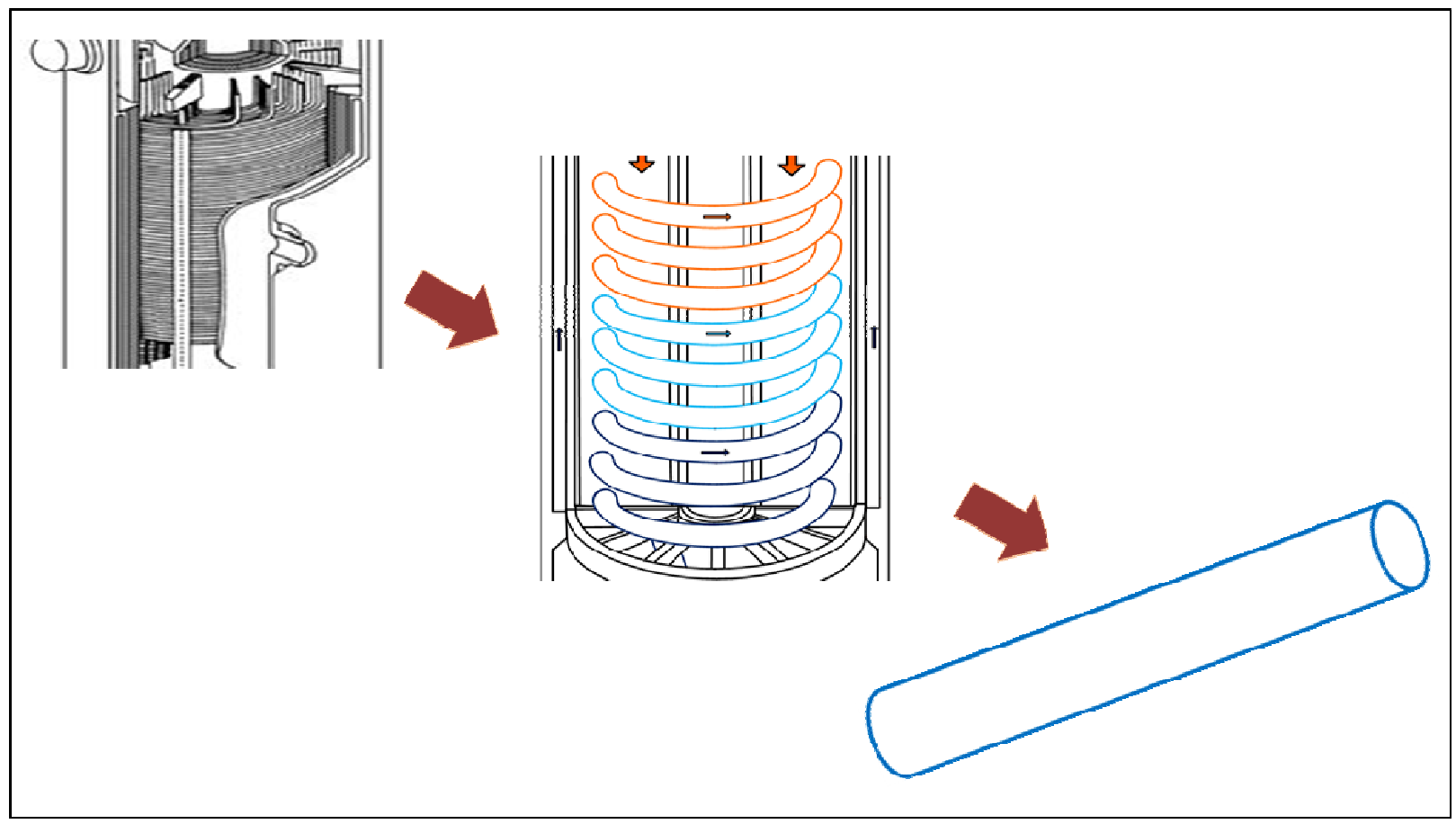

Figure 7. Helical-coil bundle simplifications.

Since all of the exact dimensions of the NGNP helical-coil steam-generator design needed for 600 MWt were unavailable, some dimensions were based on other steam-generator designs. As the design progressed, it became evident that either mass-flow rate or helical-coil heated length needed to be changed in order to attain the design primary and secondary outlet temperatures. Heated length was initially varied until the outlet primary and secondary temperatures were close to the design temperatures. Mass-flow rate was varied to reach the exact temperature. This decision was made because a variation in mass-flow rate required less coding changes than a variation in the heated length. Changing the heated length required re-nodalization of a large portion of the steam generator model. Emphasis was placed on the secondary steam outlet temperature as the parameter that governed the model design process since the steam outlet temperature directly affected process steam capabilities. Once the design was completed, the model was run at steady-state conditions until the flow within the model reached steady-state values.

The helical-coil steam-generator model used a single tube length of $144 \mathrm{~m}$ to achieve the design steam outlet temperature. This length is consistent with other helical-coil steam generator designs compared in Appendix A. Once the NGNP helical-coil steam generator design matures, the actual dimension should be used to improve model accuracy.

Part of model development was developing a transient that would be feasible using RELAP5-3D. A LOCA representing a rupture of the primary inlet and outlet pipes was chosen as the transient. The 
rupture was simulated by an exponential decrease in the primary inlet and outlet pressures. Other steam generator transient studies have also simulated LOCAs using ramp inputs for pressure (Munshi et al. 1985, Bhathagar et al. 1985, Munshi et al. 1986). Feedback from the reactor and power-conversion system were not considered in this model.

\subsection{Model Description}

The primary and secondary systems of the steam generator model are divided into several nodes. Nodes in RELAP5 are represented by hydrodynamic structures that are subdivided into volumes or heat structures. The primary or shell side system (Figure 8) starts with an inlet boundary condition made up of a time-dependent volume (TMDPVOL 110) and a time-dependent junction (TMDPJUN 115). The timedependent volume acts as a source and controls the temperature and pressure with respect to time. The time-dependent junction controls the mass-flow rate. The time-dependent volume is connected directly to the time-dependent junction, which connects to a pipe component (PIPE 120) having six volumes. PIPE 120 models the inner pipe of the cross duct, the inlet pipe, and the inner plenum. PIPE 120 is connected to ANNULUS 130 via a single junction (SNGLJUN 125). ANNULUS 130 models the upper and lower bundles regions. ANNULUS 130 contains 39 volumes, vertically oriented, with a downward flow. There are abrupt area changes between the 9 and 10 volumes, 11 and 12 volumes, and the 38 and 39 volumes, which represent the flow area change between helical-coil and straight pipe sections. ANNULUS 130 is connected to ANNULUS 140 via SNGLJUN 135. ANNULUS 140, which is vertically oriented with up-

flow, models the annular section between the inner and outer shrouds. ANNULUS 140 is connected to PIPE 150 via SNGLJUN 145. PIPE 150 represents a horizontal annular section in the cross duct. Because ANNULUS components must be oriented vertically, a PIPE must be used. PIPE 150 is connected to TMDPVOL 160 via SNGLJUN 155. TMDPVOL 160 acts as a sink for the primary system. 


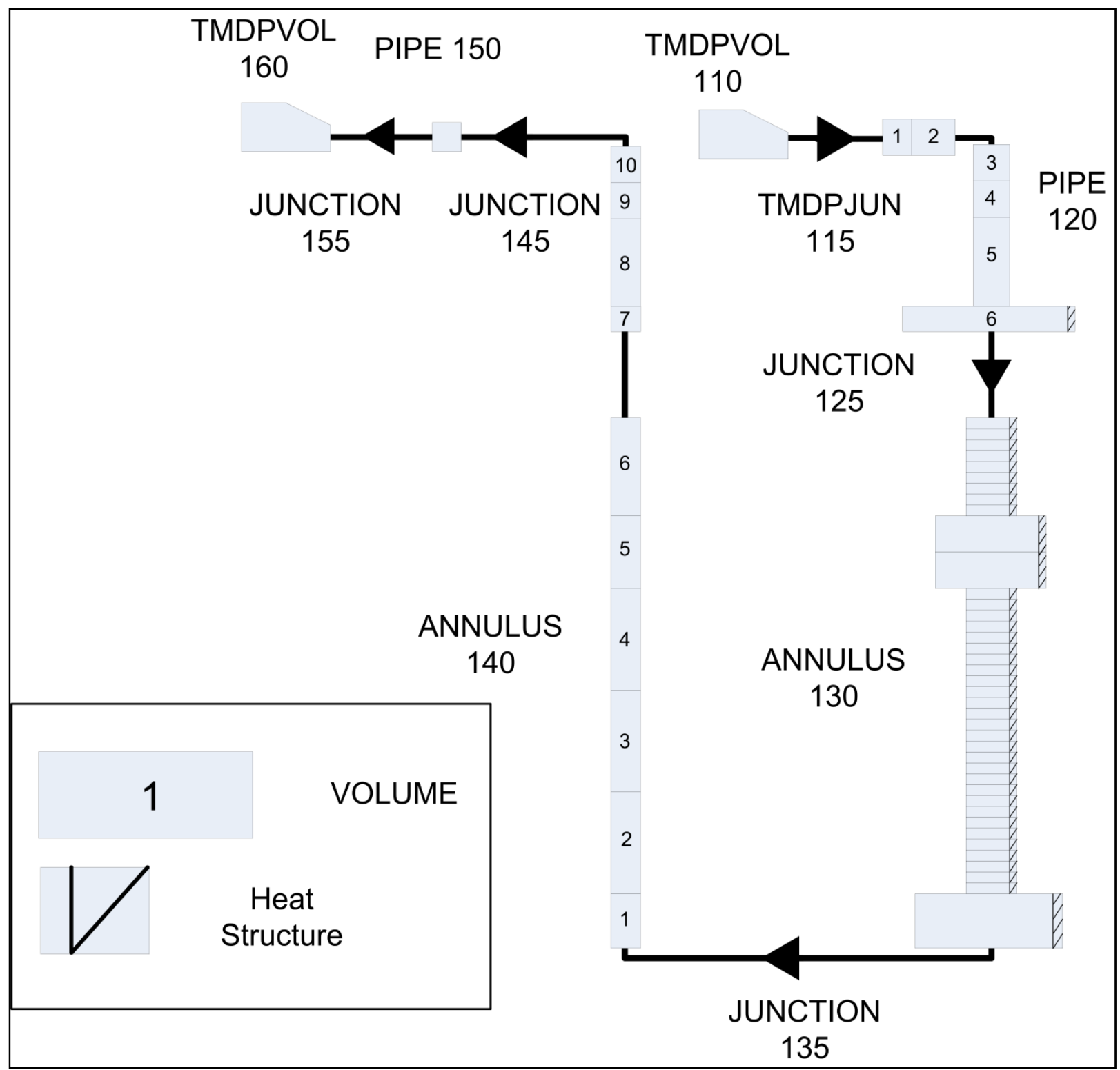

Figure 8. RELAP5-3D/ATHENA steam-generator model node visualization: primary system.

The secondary system, show in Figure 9, has inlet boundary conditions that are modeled by TMDPVOL 210 and TMDPJUN 215, providing control of the inlet temperature, pressure, and mass-flow rate. TMDPVOL 210 is connected to PIPE 220, which represents the helical coils of the steam generator. The first volume of PIPE 220 models the feed-water inlet, followed by 28 volumes with a vertical angle of 3.184 degrees. These 28 volumes model the lower helical bundle and are followed by two vertical volumes, volumes 29 and 30, which allow for the bimetallic weld to be modeled, providing a separation point for two different tube materials. Volumes 30-39 model the upper helical bundle and are followed by a vertically oriented volume. Volumes 41-44 model the steam outlet section of the steam generator. Volumes 41, 43, and 44 are horizontal while volume 42 is vertical. PIPE 220 is connected to TMDPVOL 230 via SNGLJUN 235. 


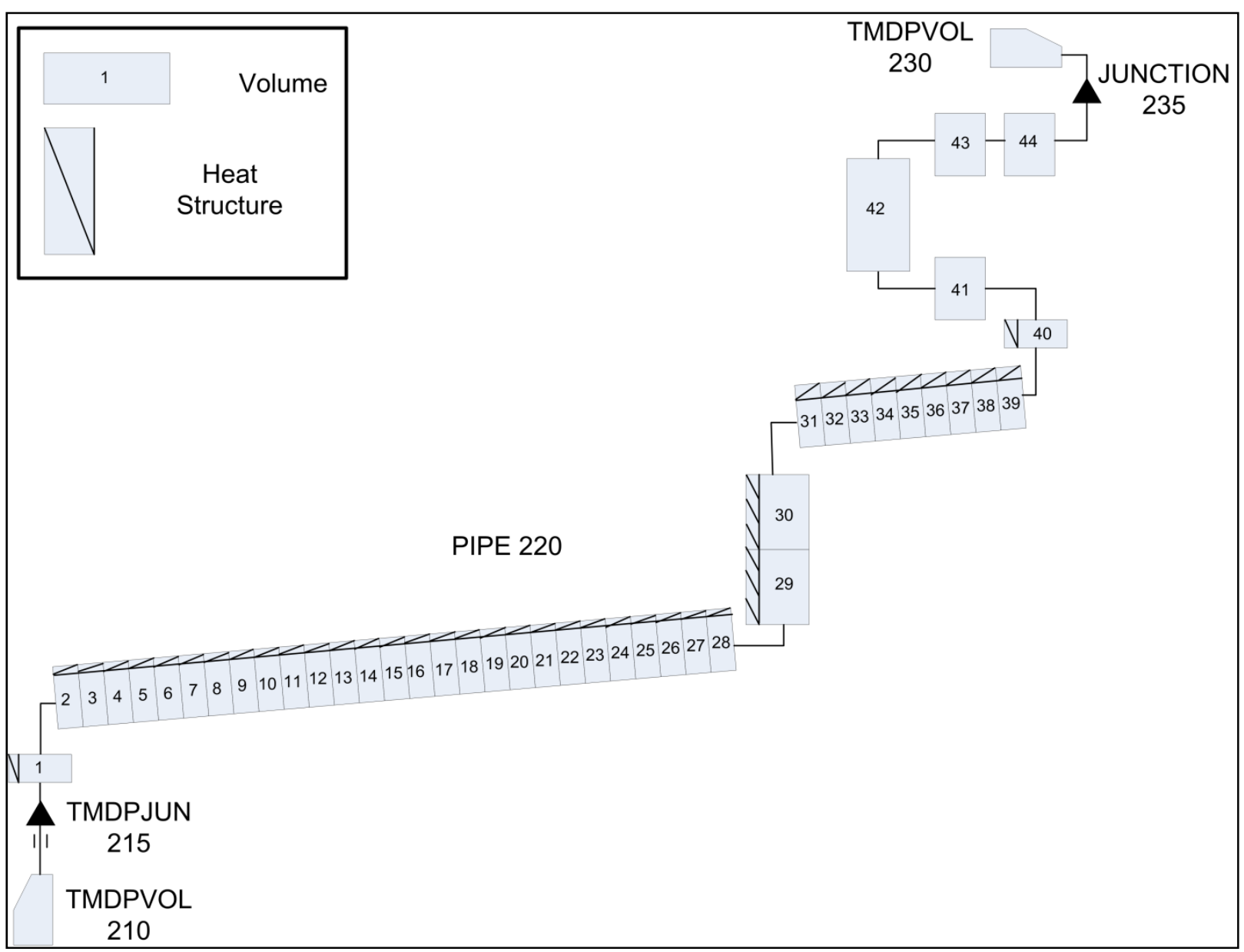

Figure 9. RELAP5-3D/ATHENA steam-generator model node visualization: secondary system.

Heat structures are used to join the primary and secondary systems together thermally. This thermal connection is how RELAP5 models heat transfer. The model is divided up into three main heat structures (220, 230, and 240) modeling the upper and lower helical-coil bundles and the short straight section just above the upper helical bundle. The subdivided heat structures are connected to volumes in a PIPE structure that nodalize the component. Since a written description of each of the connections between hydrodynamic components and heat structures would be very cumbersome, Figure 10 has been provided to show each connection. 


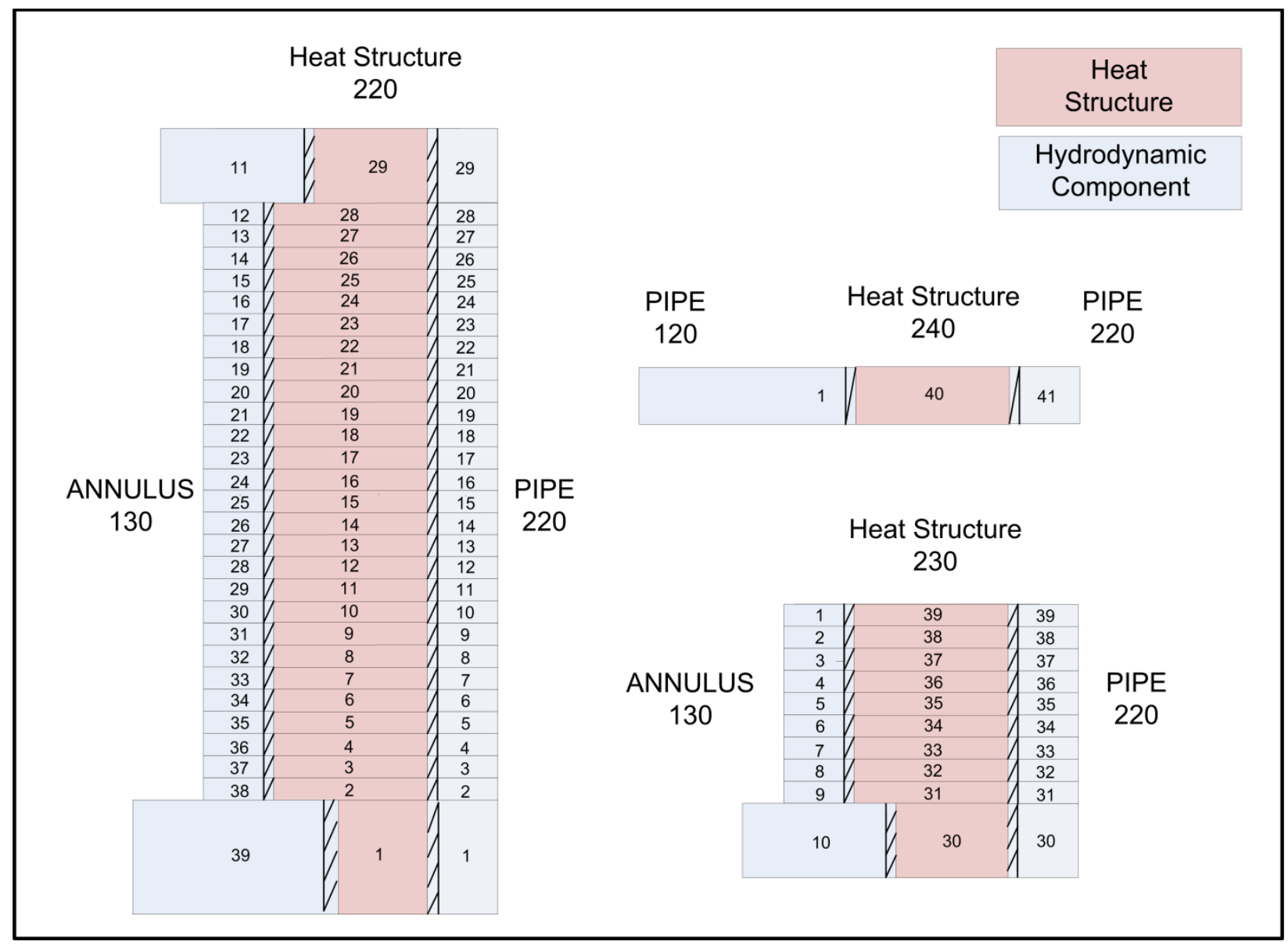

Figure 10. Heat structure connections with hydrodynamic component. 


\section{RESULTS}

\subsection{Steady-State Results}

In order to simulate a transient using RELAP5, a steady-state case must first be run. Table 5 shows the values RELAP5 returned once reaching a steady-state flow for the helical-coil steam-generator model. NGNP current design values as well as calculated values are displayed.

To achieve the desired primary and secondary outlet temperature, the secondary mass-flow rate was adjusted from the calculated value. The secondary mass-flow rate decreased from 245.31 to $232.0 \mathrm{~kg} / \mathrm{s}$ due to conservative inputs in the calculations. The single tube heated length required to achieve the desired secondary outlet temperature was $144 \mathrm{~m}$, which is consistent with steam generator tube lengths in Appendix A.

Table 5. Steady state results.

\begin{tabular}{|l|c|c|c|}
\hline \multicolumn{1}{|c|}{ Parameter } & NGNP Value & Calculated Value & $\begin{array}{c}\text { RELAP5-3D } \\
\text { Value }\end{array}$ \\
\hline Heat load, MWt & 600 & - & - \\
\hline Primary inlet temperature, ${ }^{\circ} \mathrm{C}$ & 750 & - & 757.37 \\
\hline Primary outlet temperature, ${ }^{\circ} \mathrm{C}$ & 322 & 322 & 333.35 \\
\hline Primary mass-flow rate, $\mathrm{kg} / \mathrm{s}$ & 250 & 270.17 & 270.17 \\
\hline Primary inlet pressure, $\mathrm{MPa}$ & 7.0 & - & 7.22 \\
\hline Primary outlet pressure, $\mathrm{MPa}$ & 6.976 & - & 6.982 \\
\hline Secondary inlet temperature, ${ }^{\circ} \mathrm{C}$ & 200 & - & 205.32 \\
\hline Secondary outlet temperature, ${ }^{\circ} \mathrm{C}$ & 540 & 540.04 & 540.54 \\
\hline Secondary mass-flow rate, $\mathrm{kg} / \mathrm{s}$ & 216 & 245.31 & 232.0 \\
\hline Secondary inlet pressure, $\mathrm{MPa}$ & 18.2 & - & 17.516 \\
\hline Secondary outlet pressure, $\mathrm{MPa}$ & 17.2 & - & 17.203 \\
\hline Number of tubes & 411 & - & - \\
\hline Single tube heated length, $\mathrm{m}$ & - & 144 & 144 \\
\hline Heat-transfer surface area, ${ }^{2}$ & - & 5022.51 & 5022.51 \\
\hline LMTD, ${ }^{\circ} \mathrm{C}$ & - & 162.04 & - \\
\hline Overall heat-transfer coefficient, $\mathrm{J} / \mathrm{m}^{2} \cdot{ }^{\circ} \cdot{ }^{\circ} \mathrm{C}$ & - & 737.25 & - \\
\hline
\end{tabular}

\subsection{Transient Results: Exponential Decrease in Primary Pressure}

A LOCA transient, representing a rupture of the primary inlet pipe, was simulated by an exponential decrease in the primary inlet and outlet pressures. The pressure decrease occurred over a 20 second period and decreased the inlet pressure from 7.0 to $0.1013 \mathrm{MPa}$ at the inlet and from 6.976 to $0.1013 \mathrm{MPa}$ at the outlet. In order to fully represent the LOCA transient, both inlet and outlet pressures in the timedependent volumes had to decrease at the same rate. In the event of a complete rupture, the reduction in pressure will occur over a much shorter period of time. This transient pressure decrease was chosen in order to better understand the results of a complete rupture of the inlet and outlet pipes. Table 6 shows the values used to simulate the exponential decrease in inlet and outlet pressures. Neglecting to decrease the 
outlet pressure would result in either a negative pressure drop across the primary side or back pressure, invalidating the results.

Table 6. Primary inlet/outlet pressure inputs.

\begin{tabular}{|c|c|c|}
\hline Time, $\mathbf{s}$ & Primary inlet pressure, MPa & Primary outlet pressure, MPa \\
\hline 10 & 7.2 & 6.976 \\
\hline 13 & 3.8 & 3.68 \\
\hline 16 & 2.0 & 1.941 \\
\hline 19 & 1.06 & 1.024 \\
\hline 23 & 0.45 & 0.437 \\
\hline 26 & 0.2377 & 0.2303 \\
\hline 30 & 0.1013 & 0.1013 \\
\hline
\end{tabular}

The exponential decrease in pressure, as shown in Figure 11, begins at 10 seconds and ends at 30 seconds, after which the pressure stays constant at $0.1013 \mathrm{MPa}$ at both the inlet and outlet.

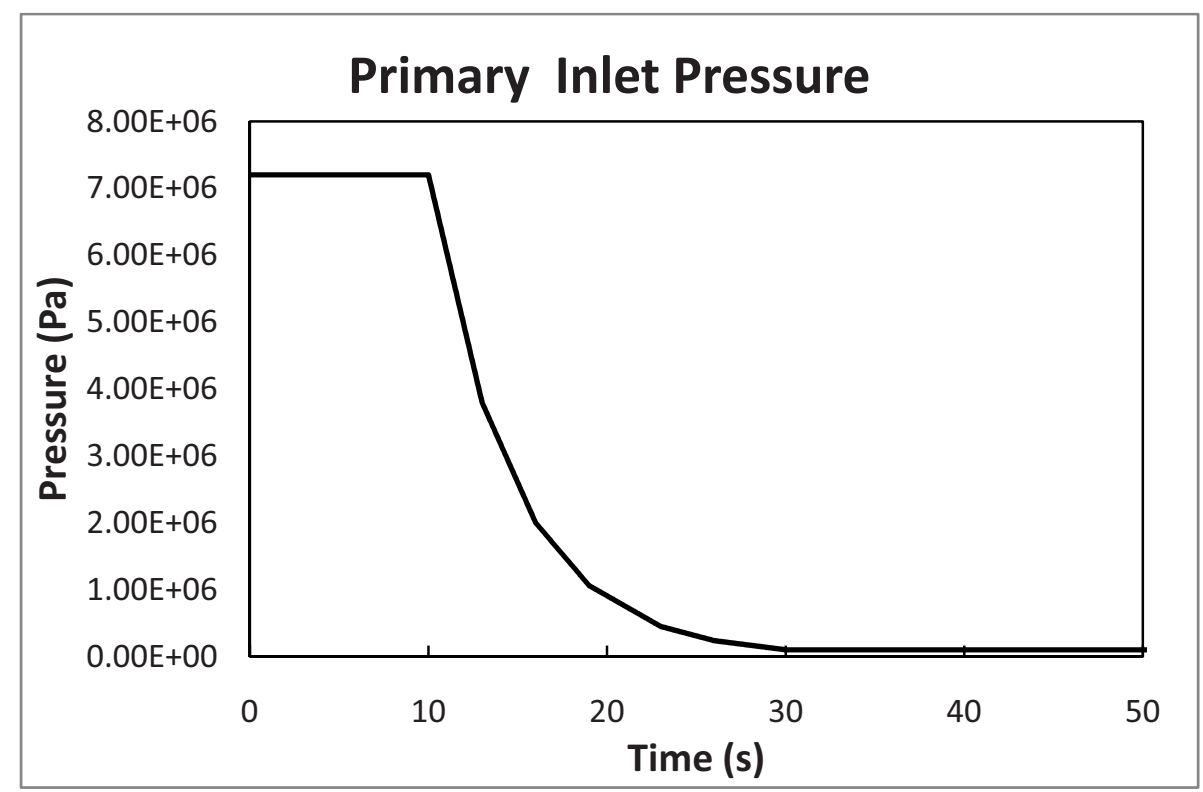

Figure 11. Exponential pressure decrease of primary inlet pressure.

As the primary pressure decreases, primary and secondary side temperatures decrease. The secondary side pressure, as shown in Figure 12, responds to the decrease in secondary temperature, initially decreasing by about $200 \mathrm{kPa}$ for the inlet and slightly decreasing for the outlet. The inlet pressure drop is greater because the rapid pressure loss in the primary system causes energy to be transferred from the secondary to the primary. 


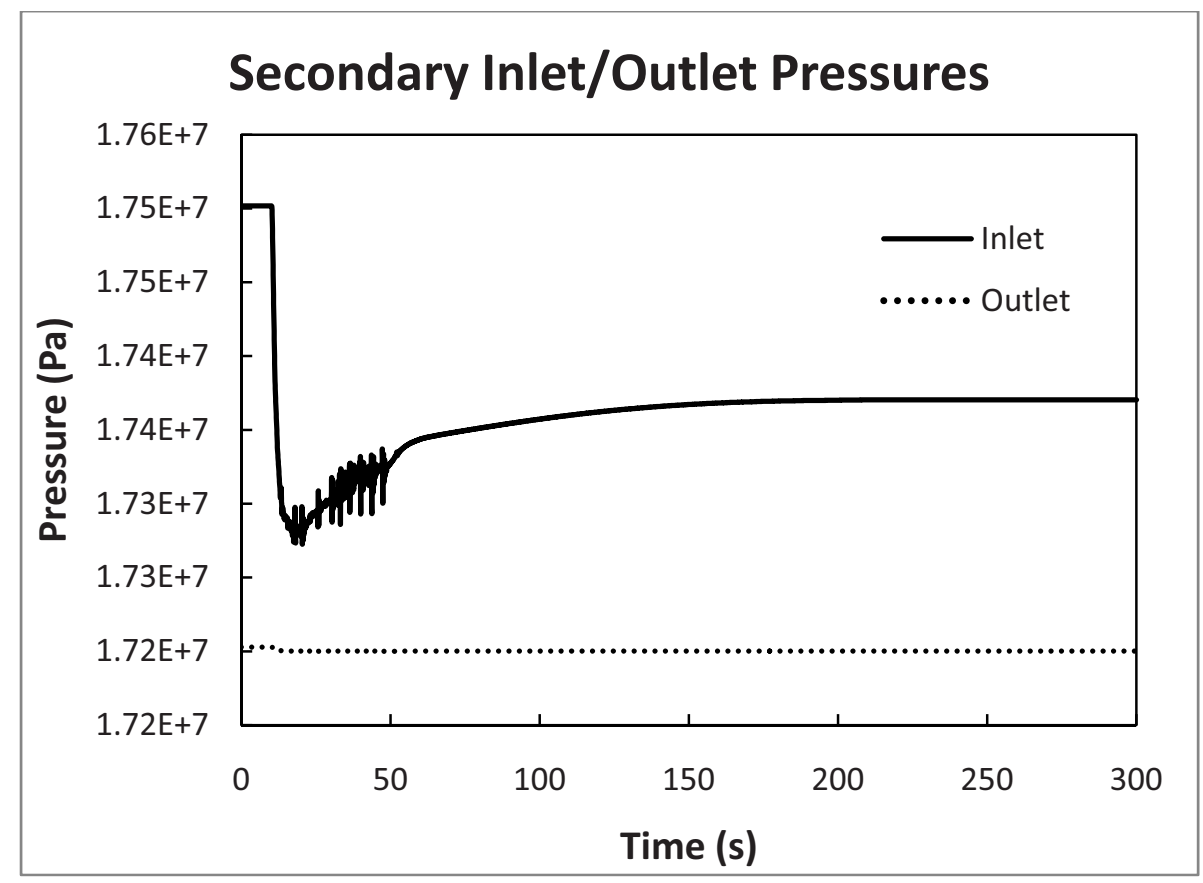

Figure 12. Secondary inlet/outlet pressure response.

The primary inlet and outlet temperature responses are shown in Figure 13. Inlet temperature decreases as the primary coolant expands in response to the decrease in pressure. The helium quickly cools until it has a lower temperature than the finishing superheater tubes. As the cooled gas comes in contact with the hotter tubes, the gas increases in temperature, creating the spike seen around 33 seconds. This spike in temperature indicates a reversal of heat transfer. Normally heat is transferred from the hot primary fluid to the colder secondary fluid, but this trend reverses after the pressure loss so that heat is transferred from the hotter secondary fluid to the now colder primary fluid. The temperature of the inlet and outlet level off as the primary and secondary temperatures begin to equalize.

The secondary inlet and outlet temperatures lag in response to the primary side changes. The outlet temperature, as shown in Figure 14, decreases rapidly as the steam condenses into a liquid. The large change in the rate of decrease of temperature around 45 seconds occurs as the steam reaches the saturation temperature. The steam then continues to condense until it all has condensed into liquid water. The temperature response becomes smooth and continues to decrease until it equals the inlet temperature, at which point the primary and secondary systems have reached a new steady-state.

The primary inlet and outlet mass-flow rate responses showed interesting results. Figure 15 indicates that there was a flow reversal for the inlet. The flow reversal occurs because of the rapid decrease in pressure at the inlet. The primary gas rushes out the inlet as the pressure decreases. The rapid loss of coolant causes the helium temperature to decrease rapidly as well. The cold primary gas comes into contact with the hot tubes, causing the gas to expand, which contributes to flow reversal. The mass-flow rates then returns to $0.0 \mathrm{~kg} / \mathrm{s}$ at 30 seconds when both the inlet and outlet pressures are equal.

While the secondary inlet mass-flow rate is held constant, the outlet mass-flow rate experiences a large decrease as shown in Figure 16. This response is caused by an entirely different phenomenon than the primary response. Due to the temperature decrease in the primary loop, the superheated steam cools, causing it to condense to liquid water. Because the helical-coil is inclined, the liquid water flows back down the tubes until the tubes are filled with water. As the tubes are filled with liquid water, the massflow rate increases back to its initial rate. 


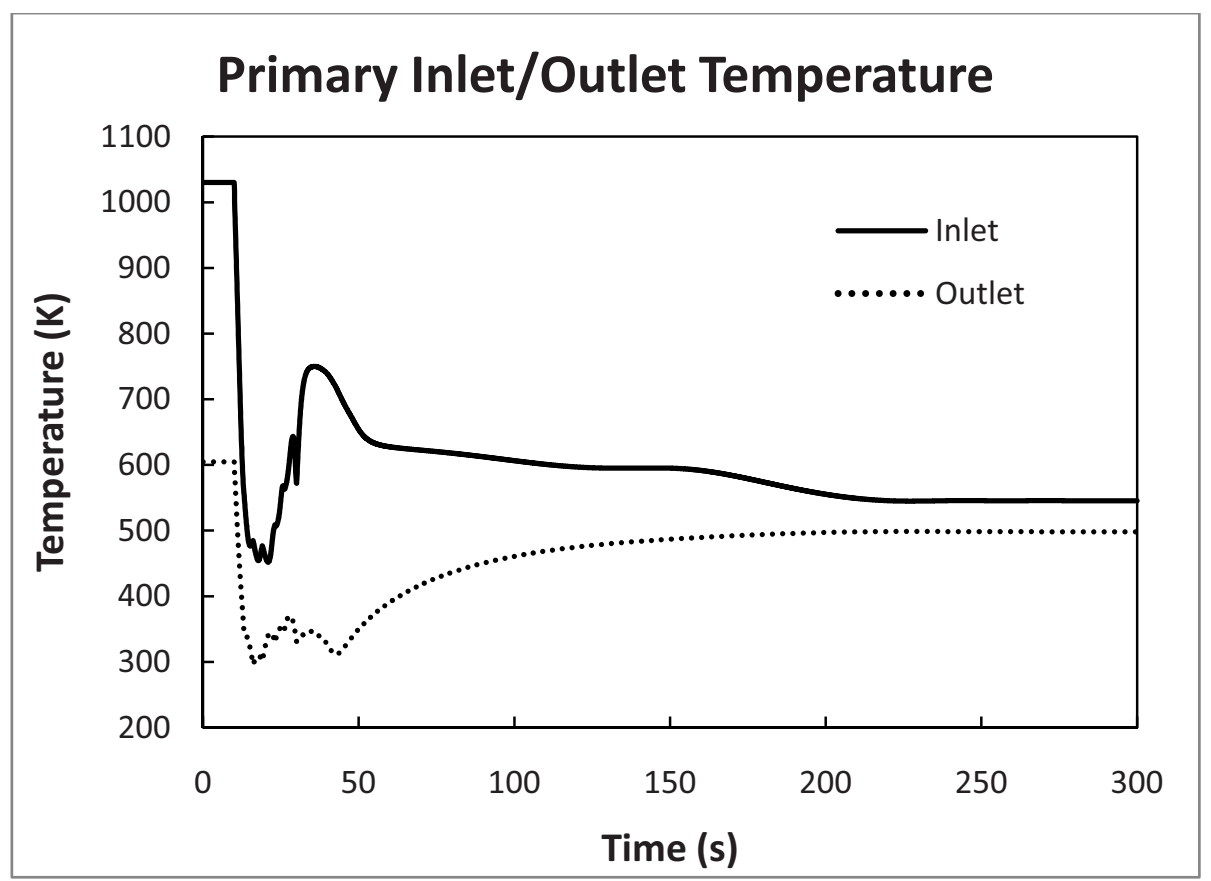

Figure 13. Primary inlet/outlet temperature response.

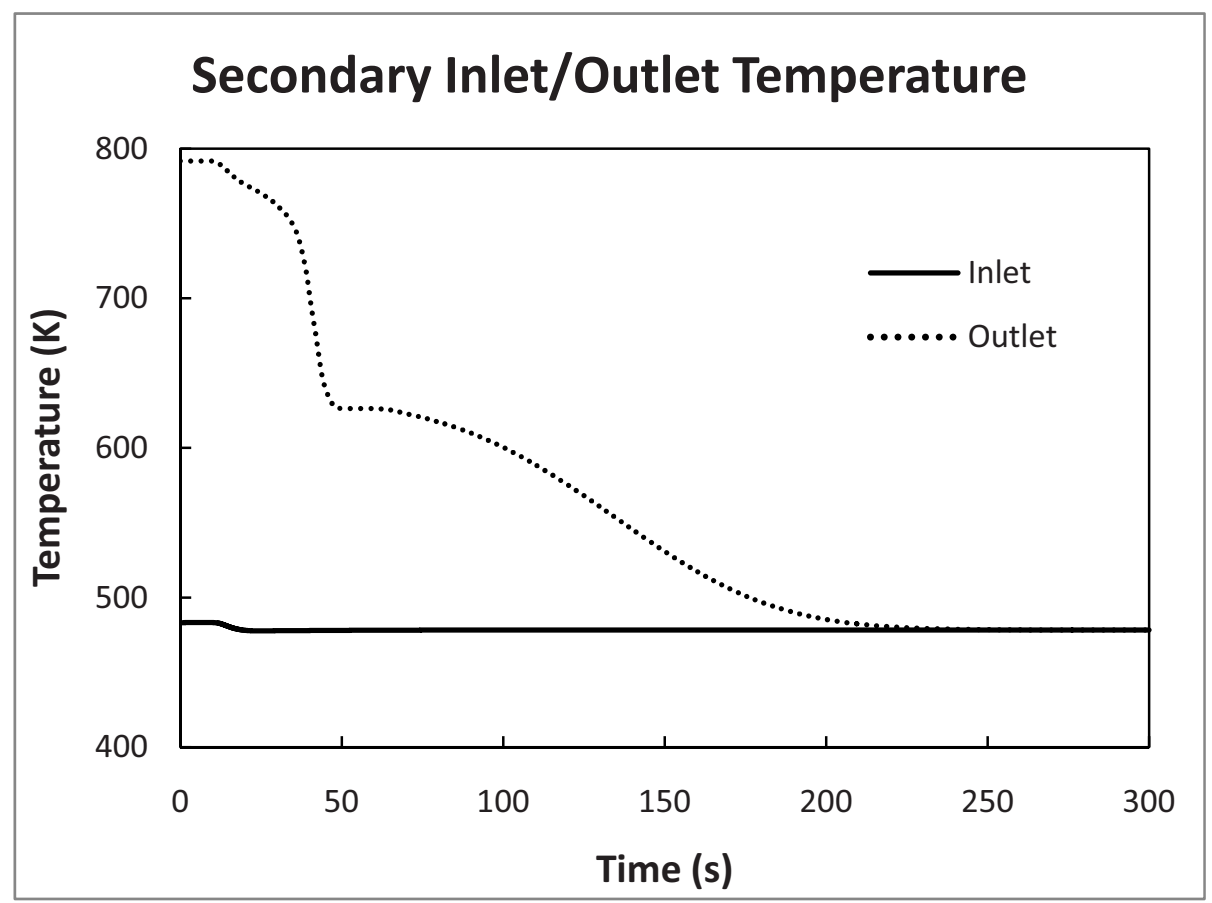

Figure 14. Secondary inlet/outlet temperature response. 


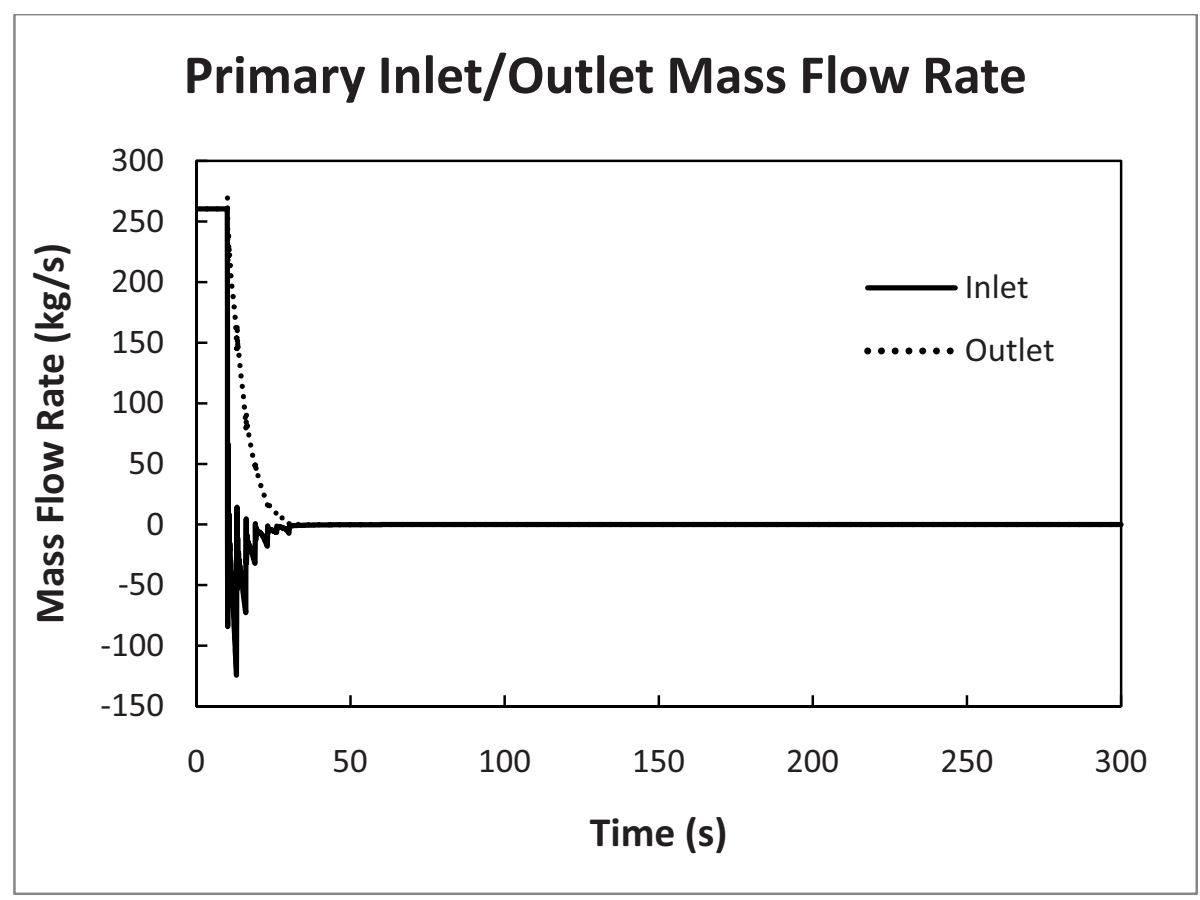

Figure 15. Primary inlet/outlet mass-flow rate response.

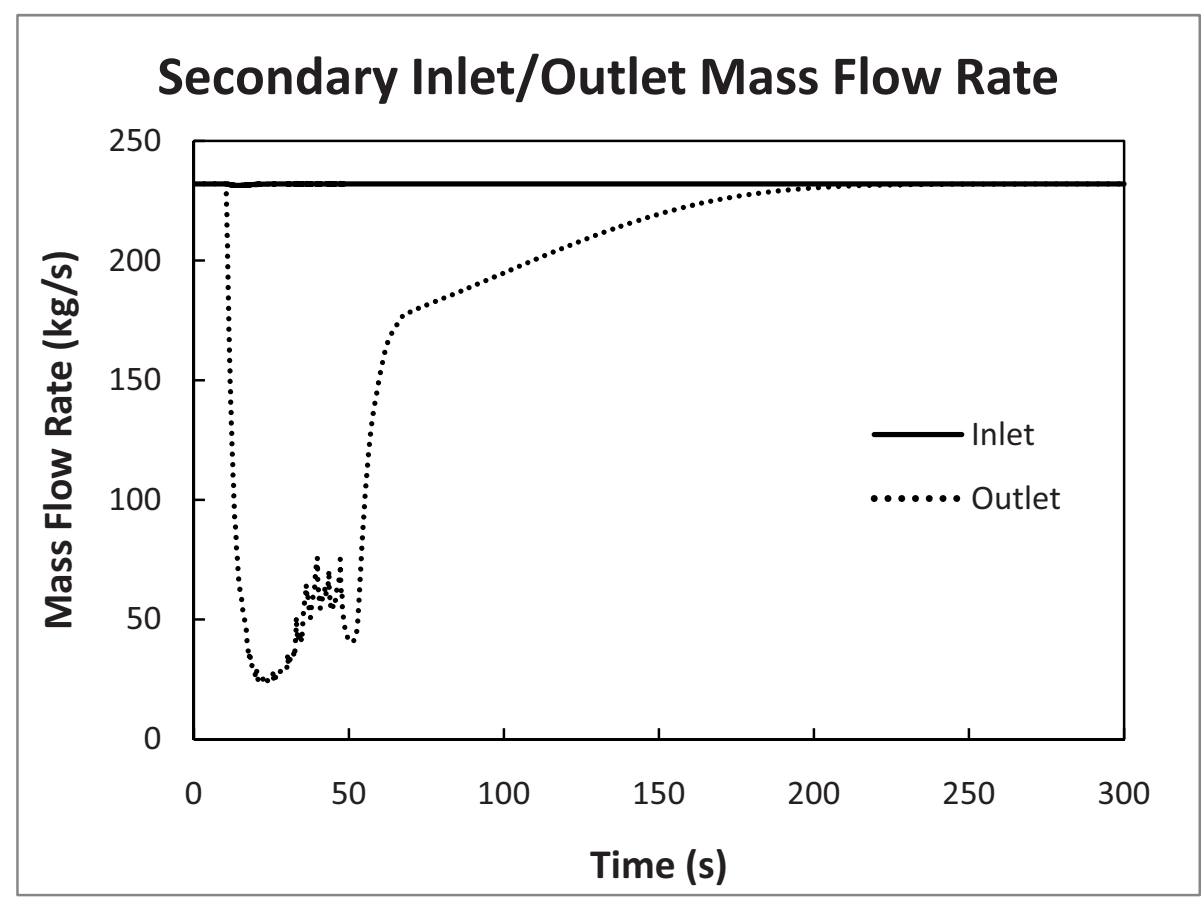

Figure 16. Secondary inlet/outlet mass-flow rate response. 


\section{CONCLUSIONS AND FUTURE WORK}

\subsection{Conclusions}

A loss of primary pressure transient was simulated as an exponential decrease of primary pressure using the RELAP5-3D helical-coil steam-generator model. Heat transfer between the primary and secondary systems experienced a reversal. The heat was initially transferred from the primary system to the secondary system. After the pressure loss, the heat was transferred from the secondary system to the primary system. The primary inlet mass-flow rate experiences a flow reversal. The steady-state model that was developed solved for the design steam outlet temperature using a lower mass-flow rate than was calculated because of conservative inputs.

\subsection{Future Work}

In order to fully simulate operational and LOCA transients within the helical-coil steam-generator model, the model must be coupled with a reactor core model. Future work includes the development of a working reactor model. Coupling the reactor and steam-generator models would allow for a feedback loop between the reactor and steam generator, realistically changing the steam-generator inlet conditions. Work will also be done on other transients including, but not limited to, start-up and shutdown operations and plugged and fouled tubes. 


\section{REFERENCES}

1. General Atomics, Nuclear Heat Supply System Point Design Study for NGNP Conceptual Design, 911167, 2009.

2. General Atomics, NGNP Steam Generator Alternatives Study, 911120, 2008.

3. Westinghouse Electric Company LLC, Next Generation Nuclear Plant: Intermediate Heat Exchanger Development and Trade Studies, NGNP-NHS-HTS-RPT-M-00004, 2009.

4. RELAP5 Code Development Team, RELAP5 Vol. 1-5, INEEL-EXT-98-00834, Rev 2.4, 2005.

5. Chang H. Oh, Eung S. Kim, and Mike Patterson, "Design Option of Heat Exchanger for the Next Generation Nuclear Plant," Journal of Engineering for Gas Turbines and Power, Vol. 132, No. 3, 2010 .

6. AREVA, NGNP with Hydrogen Production IHX and Secondary Heat Transport Loop Alternatives, 12-9076325-001, 2008.

7. Idaho National Laboratory, Next Generation Nuclear Plant Project, 2009 Status Report, INL/EXT09-17505, May 2009.

8. Idaho National Laboratory, Next Generation Nuclear Plant Project Technology Development Roadmaps: The Technical Path Forward for 750-800 ${ }^{\circ}$ R Reactor Outlet Temperature, INL/EXT-0916598, August 2009.

9. Piyush Sabharwall, Engineering Design Elements of a Two-Phase Thermosyphon to Transfer NGNP Thermal Energy to a Hydrogen Plant, INL-EXT-09-15383, 2009.

10. NGNP Senior Advisory Group, "Senior Advisory Group Meeting Reference Configuration," Meeting Minutes, January 28, 2009.

11. P. Munshi, R. Bhatnagar, and K.S. Ram, "Steam Generator Transient Studies Using a Simplified Two-Fluid Computer Code" Ann. Nucl. Energy, Vol. 12, No. 3, 1985, pp. 155-157.

12. P. Munshi, K. S. Ram, M. S. Kalra and D. V. Rao, "Steam-Generator Simulation With NonEquilibrium Two-Phase Flow Models," Ann. Nucl. Energy, Vol. 13, No. 11, 1986, pp. 617-621.

13. R. Bhatnagar, P. Munshi, and K. S. Ram, "A Simplified Two-Fluid Model of a Steam Generator for Digital Simulation of Operation Transients," Ann. Nucl. Energy, Vol. 12, No. 7, 1985, pp. 349-355.

14. P.E MacDonald, P. D. Bayless, H. D. Gougar, R. L. Moore, A. M. Ougouag, R. L. Sant, J. W. Sterbentz, and W. K. Terry, " The Next Generation Nuclear Plant - Insights Gained from the INEEL Point Design Studies,” INEEL/CON-04-01563 PREPRINT, 2004.

15. Gilbert Melese and Robert Katz, "Thermal and Flow Design of Helium-Cooled Reactors," American Nuclear Society, 1984.

16. Electric Power Research Institute, "Steam Generator Reference Book Volume I," Electric Power Research Institute, Inc, 1994, EPRI TR-103824s-V1R1.

17. Idaho National Laboratory, Pre-conceptual Design Report, INL/EXT-07-12937, 2007.

18. D.G. Prabhanjan, G.S.V. Ragbavan, and T.J. Rennie, "Comparison of Heat Transfer Rates Between a Straight Tube Heat Exchanger and a Helically Coiled Heat Exchanger," International

Communications in Heat and Mass Transfer, Vol. 29 No. 2, 2002, pp. 185-191 


\section{Appendix A}

Comparison of Heat Exchangers Reference Next Generation Nuclear Plant: Intermediate Heat Exchanger Development and Trade Studies 


\section{Appendix A \\ Comparison of Heat Exchangers Reference Next Generation Nuclear Plant: Intermediate Heat Exchanger Development and Trade Studies}

Table 7. Comparison of Heat Exchanger (Westinghouse Electric Company LLC, 2009).

\begin{tabular}{|c|c|c|c|c|c|c|c|c|c|}
\hline Section/Page & $\mathrm{NA} / \mathrm{S}$ & $\mathrm{NA} / \mathrm{S}$ & $3.3 .1 .1 .1 / 21$ & $3.3 .1 .2 / 31$ & $5.4 .2 / 192$ & $4.3 .1 .2 / 51$ & $4.3 .1 .2 / 51$ & $4.3 .1 .2 / 51$ & $2.4 / 55$ \\
\hline Source & INL & INL & Sulzer/KVK & JAERI/HTTR & AREVA & GA/Toshiba & GA/Toshiba & GA/Toshiba & PBMR \\
\hline Total Load, MWt & 612 & 612 & 10 & 10 & 580 & 534 & 216 & 384 & 510 \\
\hline Number of IHXs & 1 & 1 & 1 & 1 & 2 & 3 & 3 & 3 & 1 \\
\hline Load, MWt & 612 & 612 & 10 & 10 & 290 & 178 & 72 & 128 & 510 \\
\hline HX Type & Helical Coil & PCHE & Helical Coil & Helical Coil & Helical Coil & Helical Coil & Helical Coil & Helical Coil & PFHE \\
\hline \multicolumn{10}{|l|}{ Primary Side } \\
\hline Tin, ${ }^{\circ} \mathrm{C}$ & 900 & 900 & 950 & 950 & 900 & 900 & 900 & 750 & 800 \\
\hline Tout, ${ }^{\circ} \mathrm{C}$ & 594.5 & 594.5 & 293 & 390 & 490 & 480 & 750 & 481 & 268 \\
\hline Nominal Pressure, $\mathrm{MPa}$ & 7 & 7 & 4 & & 5 & 7 & 7 & 7 & 8.7 \\
\hline Flow Rate, $\mathrm{kg} / \mathrm{s}$ & 385 & 385 & 2.95 & 12 & 136 & 81.8 & 91.96 & 91.96 & 185 \\
\hline \multicolumn{10}{|l|}{ Secondary Side } \\
\hline Tin, ${ }^{\circ} \mathrm{C}$ & 492.5 & 492.5 & 220 & 330 & 415 & 308 & 673 & 312 & 218 \\
\hline Tout, ${ }^{\circ} \mathrm{C}$ & 884.8 & 884.8 & 900 & 860 & 825 & 700 & 875 & 673 & 750 \\
\hline Nominal Pressure, $\mathrm{MPa}$ & 7.6 & 7.6 & 4 & & 5.5 & 7 & 7 & 7 & 8.9 \\
\hline Flow Rate, $\mathrm{kg} / \mathrm{s}$ & 300 & 300 & 2.85 & 12 & 136 & 87.64 & 68.44 & 68.44 & 185 \\
\hline LMTD, ${ }^{\circ} \mathrm{C}$ & 46 & 46 & 61 & 90 & 75 & 186 & 46 & 117 & 50 \\
\hline \multicolumn{10}{|l|}{ Tubes } \\
\hline Number & 5025 & & 119 & 96 & 2966 & 500 & 1025 & 914 & \\
\hline $\mathrm{OD}, \mathrm{mm}$ & 20 & & 22 & 31.8 & 21 & 45 & 31.8 & 31.8 & \\
\hline Thickness, mm & 1 & & 2 & 3.5 & 2.2 & 5 & 3.5 & 3.5 & \\
\hline Length, $\mathrm{m}$ & 42.9 & & 43 & & 18.3 & 22.05 & 21.39 & 17.62 & \\
\hline Inner Coil Diameter, mm & 490 & & & & 1500 & 1870 & 1600 & 1600 & \\
\hline Outer Coil Diameter, $\mathrm{mm}$ & 4600 & & & & 3490 & 4080 & 3950 & 3762 & \\
\hline Coil Height, m & 9.86 & & & & 7.8 & 4.58 & 4.45 & 3.66 & \\
\hline Coil Layer & & & & & & 18 & 26 & 24 & \\
\hline \multicolumn{10}{|l|}{ Modules } \\
\hline Number & & 34 & & & & & & & 180 \\
\hline Length, mm & & 430 & & & & & & & 553.7 \\
\hline Width, mm & & 600 & & & & & & & 50 \\
\hline Height, mm & & 600 & & & & & & & 1000 \\
\hline HT Core Volume, $\mathrm{m}^{3}$ & 162.0 & 5.29 & & & 60.8 & 47.3 & 45.6 & 33.3 & 4.98 \\
\hline Total HT Area, $\mathrm{m}^{2}$ & 13540 & 5805 & 348 & & 3581 & 1714 & 2190 & 1609 & 16879 \\
\hline $\mathrm{U}, \mathrm{W} / \mathrm{m}^{2} * \mathrm{~K}$ & 1189 & 2313 & 473 & & 1080 & 559 & 711 & 680 & 604 \\
\hline
\end{tabular}




\begin{tabular}{|c|c|c|c|c|c|c|c|c|c|}
\hline \multicolumn{10}{|l|}{ Vessel } \\
\hline $\mathrm{ID}, \mathrm{mm}$ & & & 2400 & 2000 & 6380 & 5000 & 5000 & 4750 & 3500 \\
\hline Height, mm & & & 24980 & 11000 & & 18350 & 18500 & 17500 & 7819 \\
\hline Approx. Volume, $\mathrm{m}^{3}[2]$ & 163.8 & & 177 & 61 & & 275 & 278 & 246 & 70 \\
\hline Surface Efficiency, $\mathrm{kW} / \mathrm{m}^{3}[3]$ & & & 29 & & 81 & 104 & 33 & 80 & 30 \\
\hline Core Compactness, $\mathrm{MW} / \mathrm{m}^{3}$ & 3.8 & 116 & & & 5 & 4 & 2 & 4 & 102 \\
\hline $\mathrm{HX}$ compactness, $\mathrm{MW} / \mathrm{m}^{3}$ & 3.74 & & 0.06 & 0.16 & & 0.65 & 0.26 & 0.52 & 7.29 \\
\hline \multicolumn{10}{|c|}{$\begin{array}{l}\text { Notes: } \\
\text { [1] AREVA IHX diameter from Fig. 5-5, Ref. 3-6; believed to be flange OD } \\
\text { [2] Assumes spherical heads } \\
\text { [3] Heat Transfer Active Area Only }\end{array}$} \\
\hline
\end{tabular}


Appendix B

\section{Transient Helical-coil Steam Generator, RELAP5-3D Input Deck}




\section{Appendix B \\ Transient Helical-coil Steam-generator RELAP5-3D Input Deck with Comments}

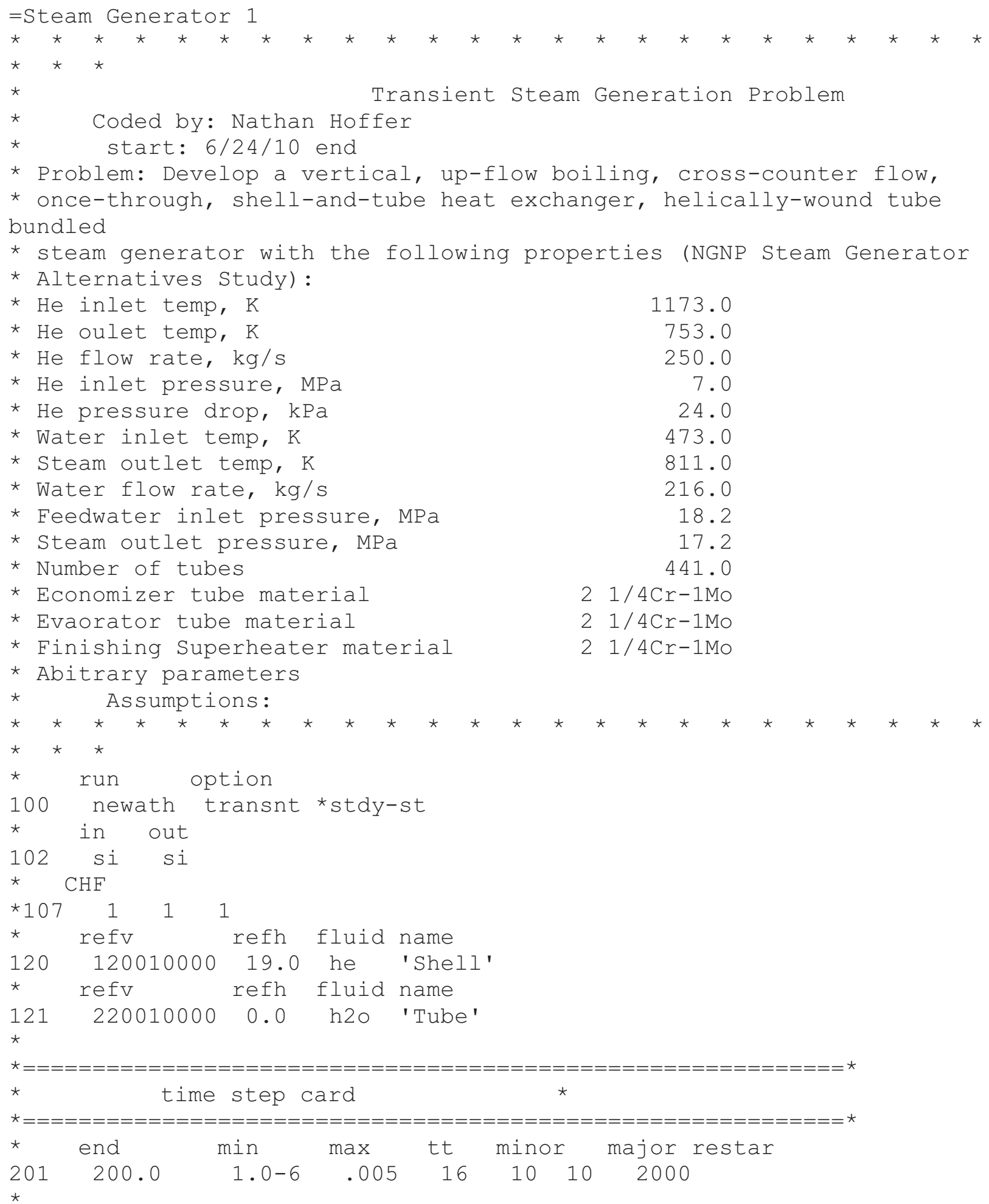




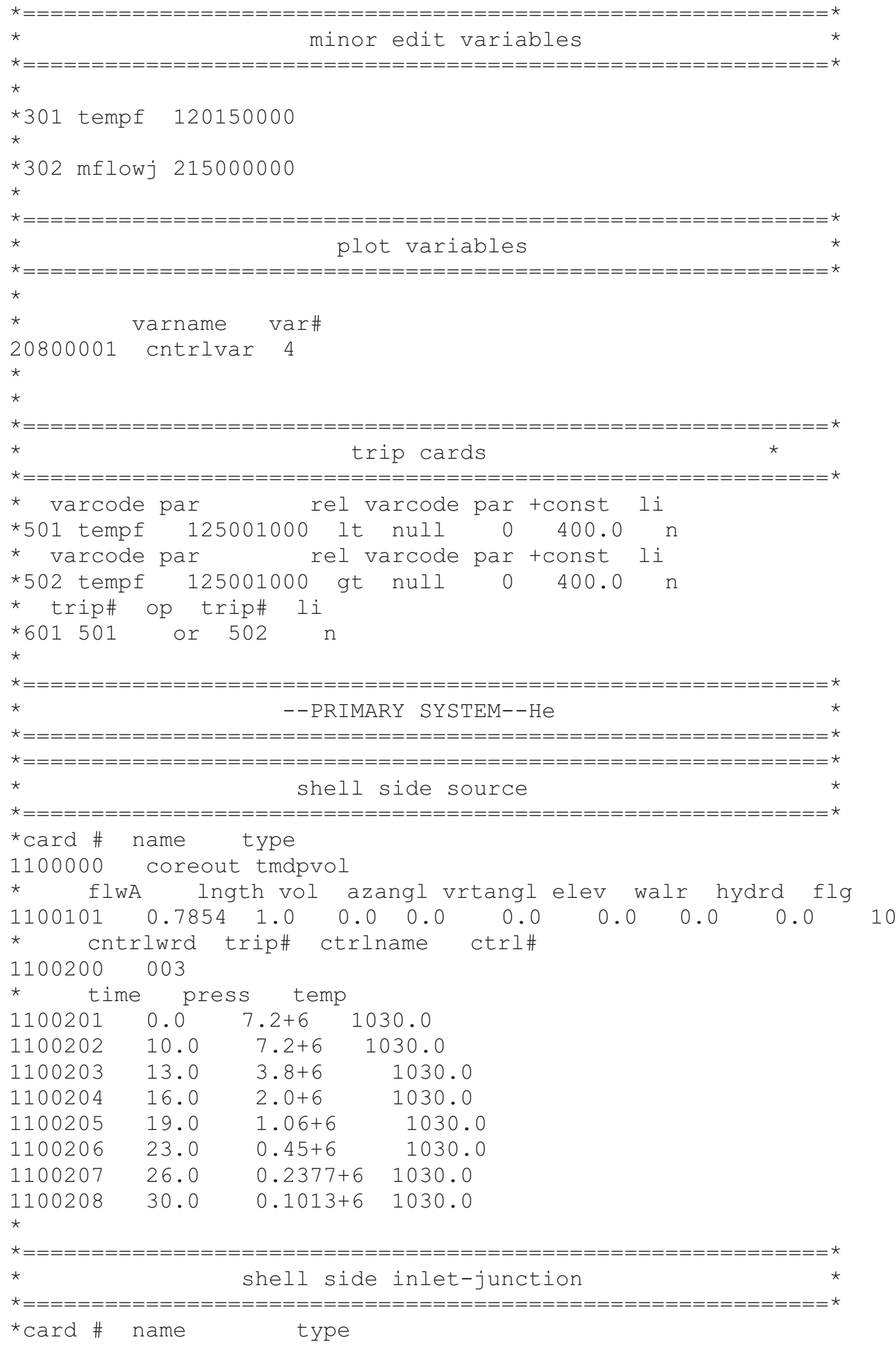




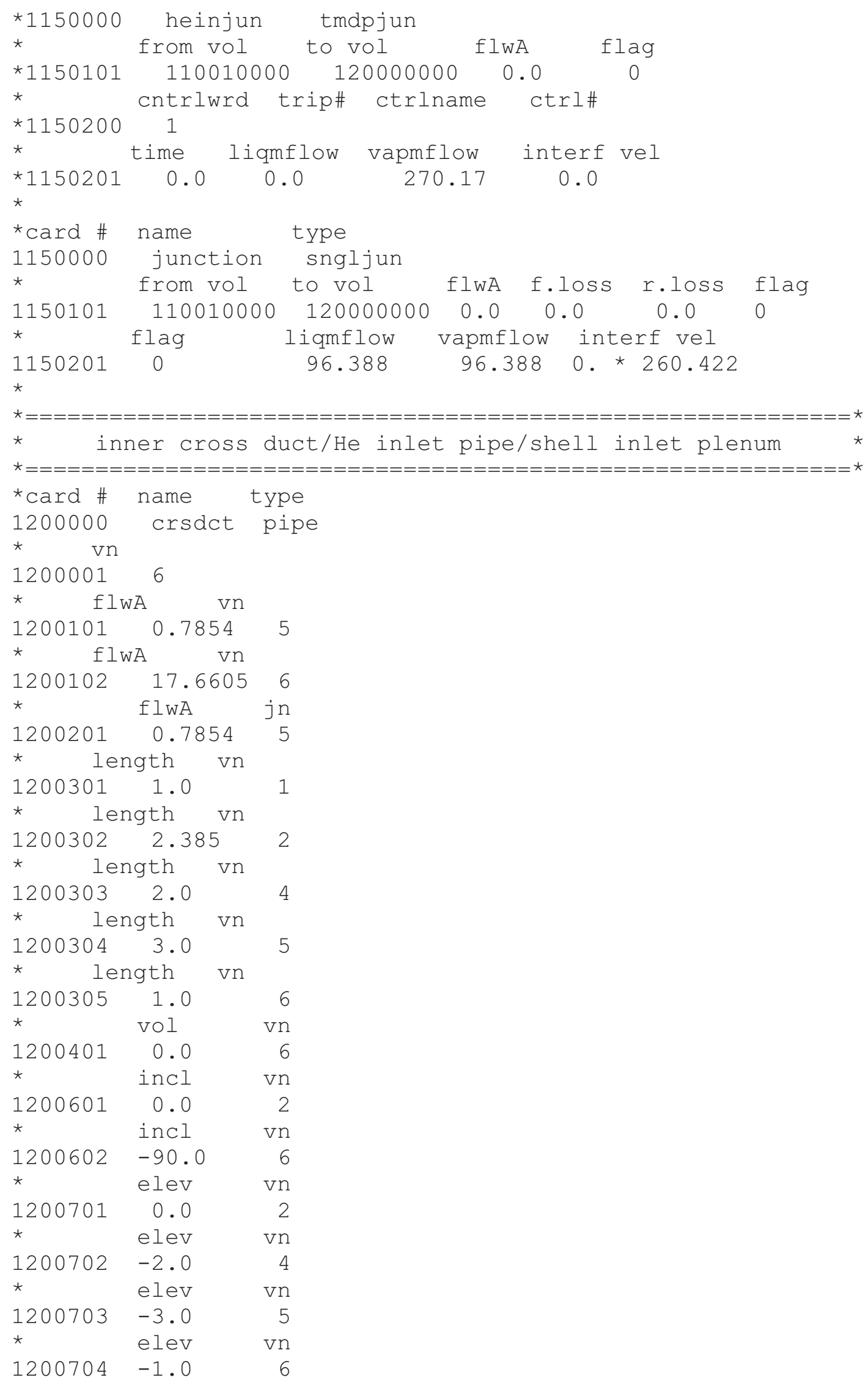




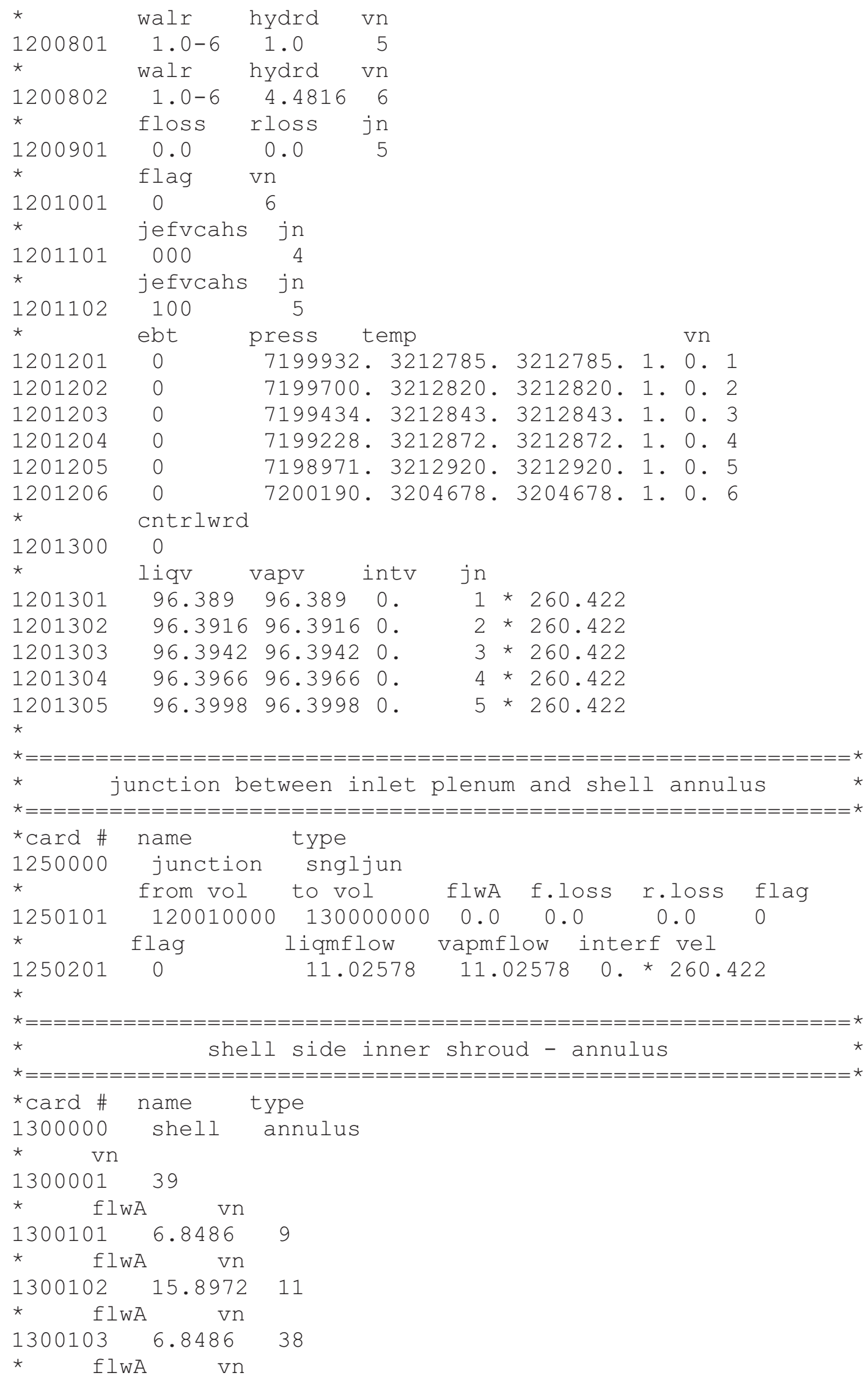




\begin{tabular}{|c|c|c|c|}
\hline 1300104 & 17.8139 & 39 & \\
\hline * & $f l w A$ & jn & \\
\hline 1300201 & 6.8486 & 8 & \\
\hline & $f l w A$ & jn & \\
\hline 300202 & 15.8972 & 9 & \\
\hline & $f l w A$ & $j n$ & \\
\hline 1300203 & 6.8486 & 38 & \\
\hline & igth $\quad v n$ & & \\
\hline 1300301 & 0.1666 & 9 & \\
\hline & igth vn & & \\
\hline 1300302 & 1.0 & 11 & \\
\hline & igth vn & & \\
\hline 1300303 & 0.1666 & 38 & \\
\hline & igth $\quad v n$ & & \\
\hline 1300304 & 3.0 & 39 & \\
\hline & vol & vn & \\
\hline 1300401 & 0.0 & 39 & \\
\hline$\star$ & incl & vn & \\
\hline 1300601 & -90.0 & 39 & \\
\hline 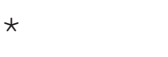 & elev & vn & \\
\hline 1300701 & -0.1666 & 9 & \\
\hline 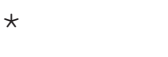 & elev & vn & \\
\hline 1300702 & -1.0 & 11 & \\
\hline 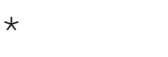 & elev & $\mathrm{vn}$ & \\
\hline 1300703 & -0.1666 & 38 & \\
\hline * & elev & vn & \\
\hline 1300704 & -3.0 & 39 & \\
\hline$\star$ & walr & hydrd & vn \\
\hline 1300801 & $1.0-6$ & 0.7509 & 9 \\
\hline$\star$ & walr & hydrd & vn \\
\hline 1300802 & $1.0-6$ & 3.1057 & 11 \\
\hline 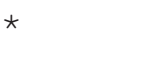 & walr & hydrd & $\mathrm{vn}$ \\
\hline 1300803 & $1.0-6$ & 0.7509 & 38 \\
\hline$\star$ & walr & hydrd & $\mathrm{vn}$ \\
\hline 1300804 & $1.0-6$ & 4.5026 & 39 \\
\hline * & floss & rloss & $j n$ \\
\hline 1300901 & 0.0 & 0.0 & 8 \\
\hline * & floss & rloss & $j n$ \\
\hline 1300902 & 0.0 & 0.0 & 9 \\
\hline 夫 & floss & rloss & $j n$ \\
\hline 1300903 & 0.0 & 0.0 & 10 \\
\hline 夫 & floss & rloss & $j n$ \\
\hline 1300904 & 0.0 & 0.0 & 38 \\
\hline * & flag & vn & \\
\hline 1301001 & 0 & 39 & \\
\hline * & jefvcahs & jn & \\
\hline 1301101 & 100 & 8 & \\
\hline * & jefvcahs & jn & \\
\hline 1301102 & 000 & 9 & \\
\hline$\star$ & jefvcahs & jn & \\
\hline 301103 & 100 & 10 & \\
\hline & jefvcahs & $j n$ & \\
\hline
\end{tabular}




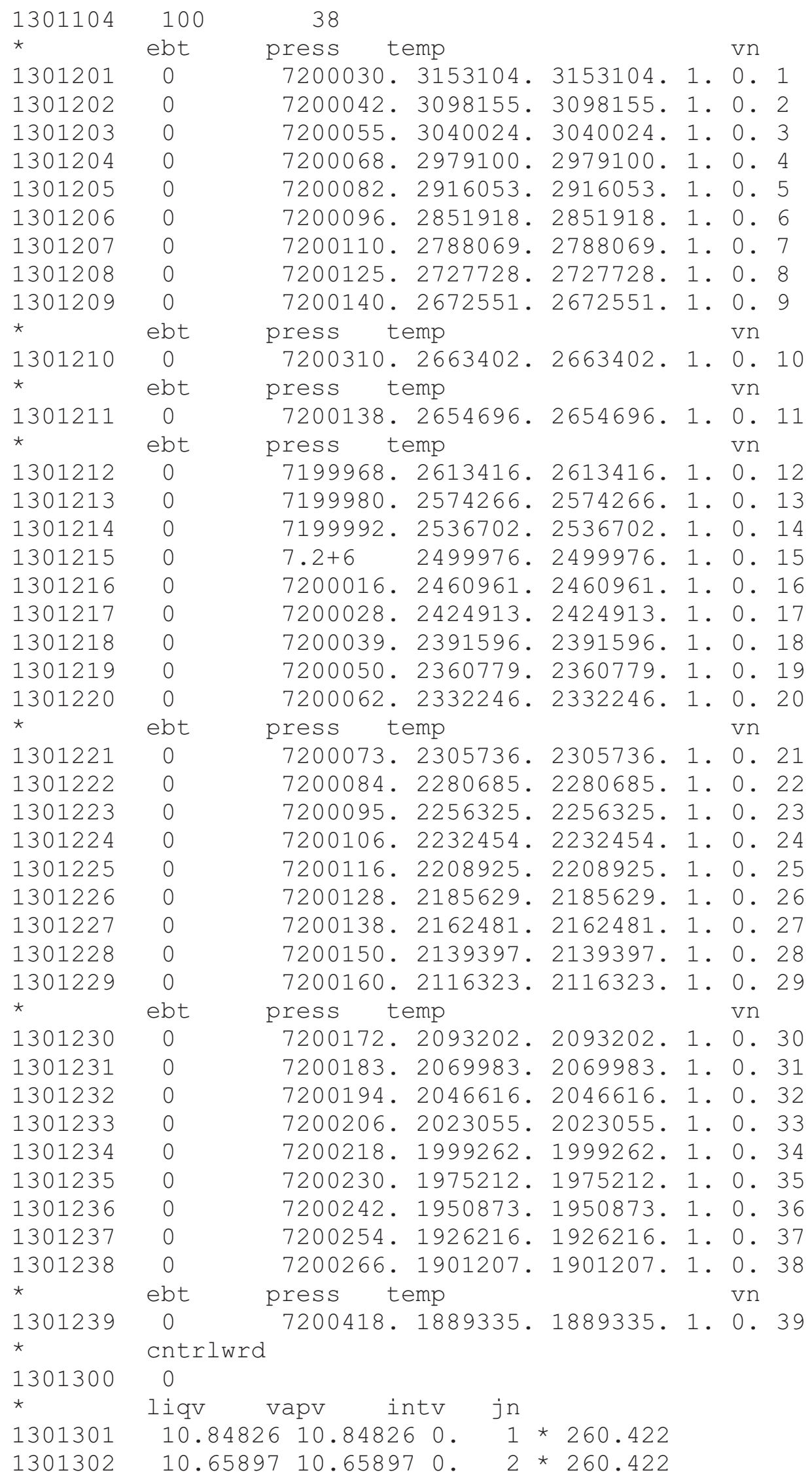




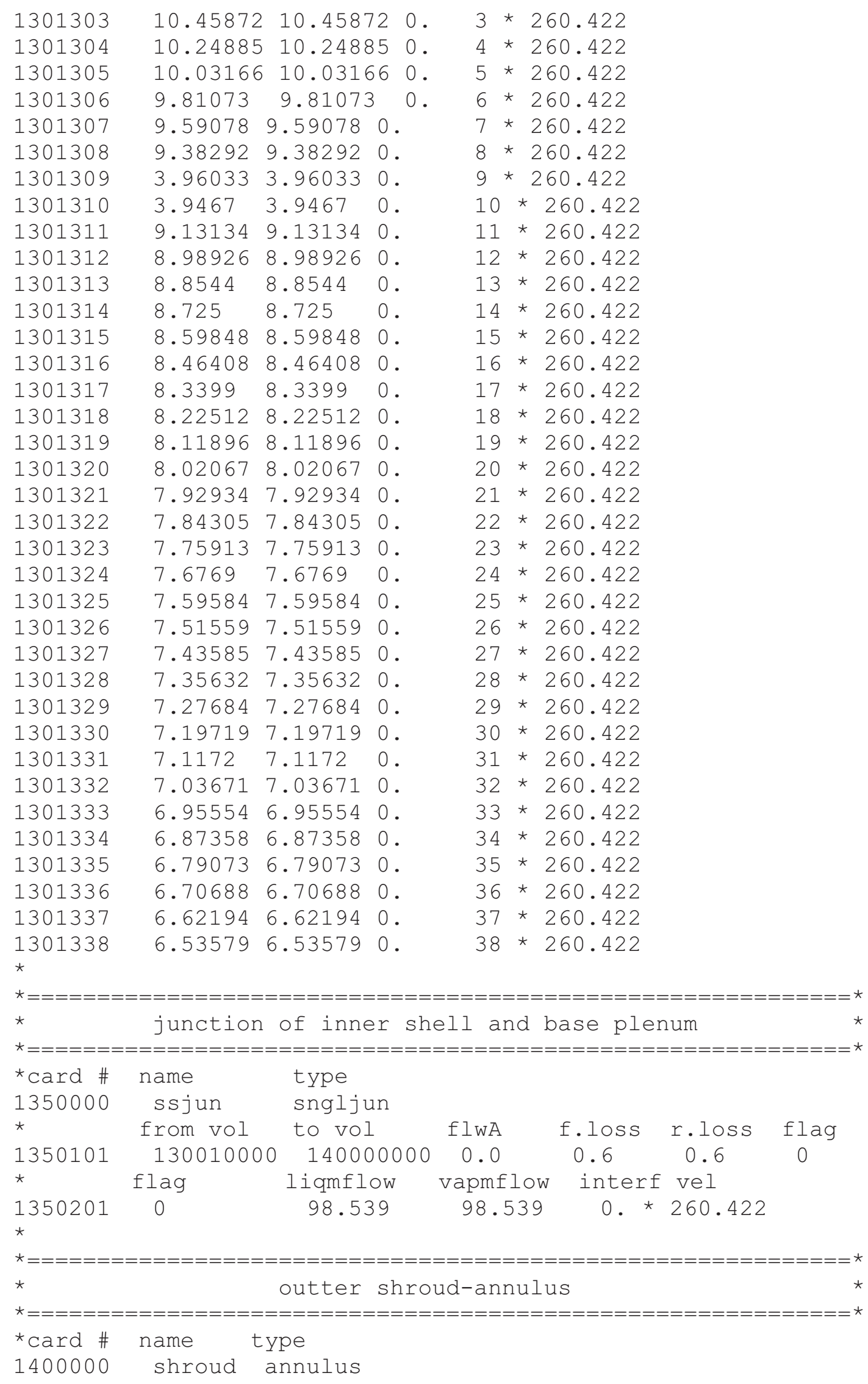




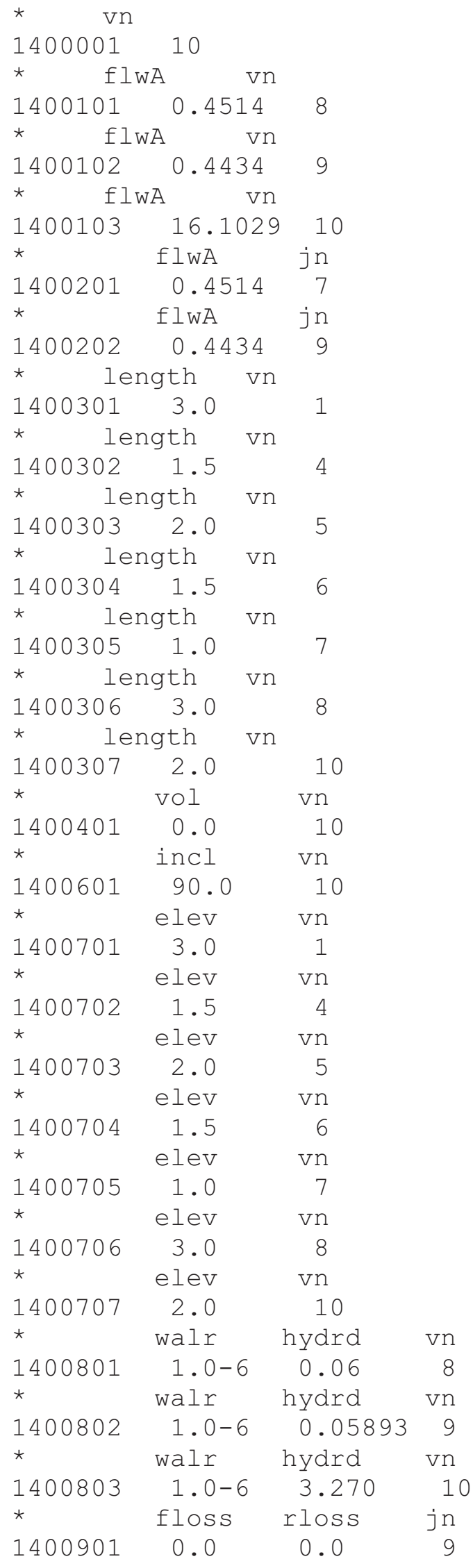




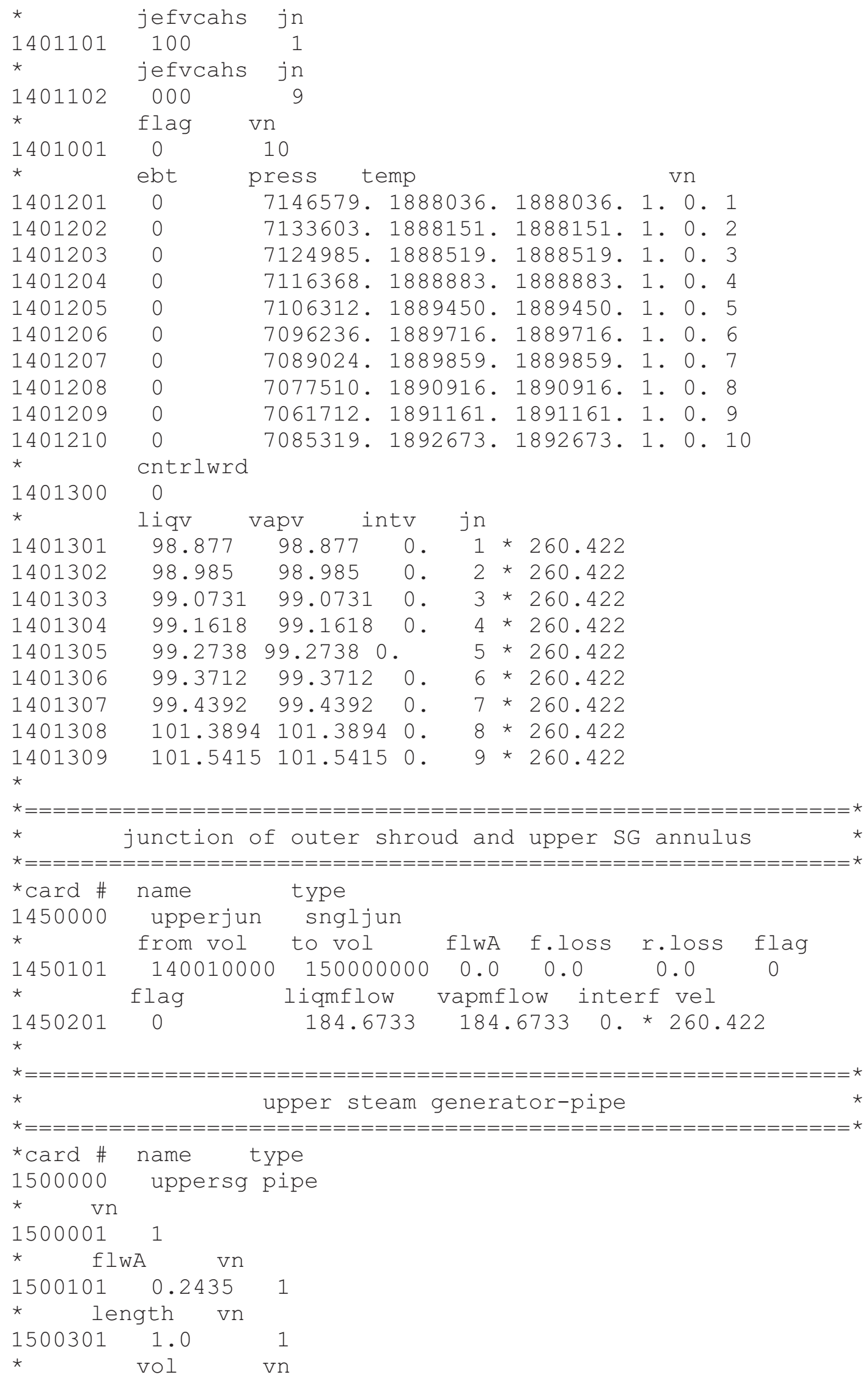




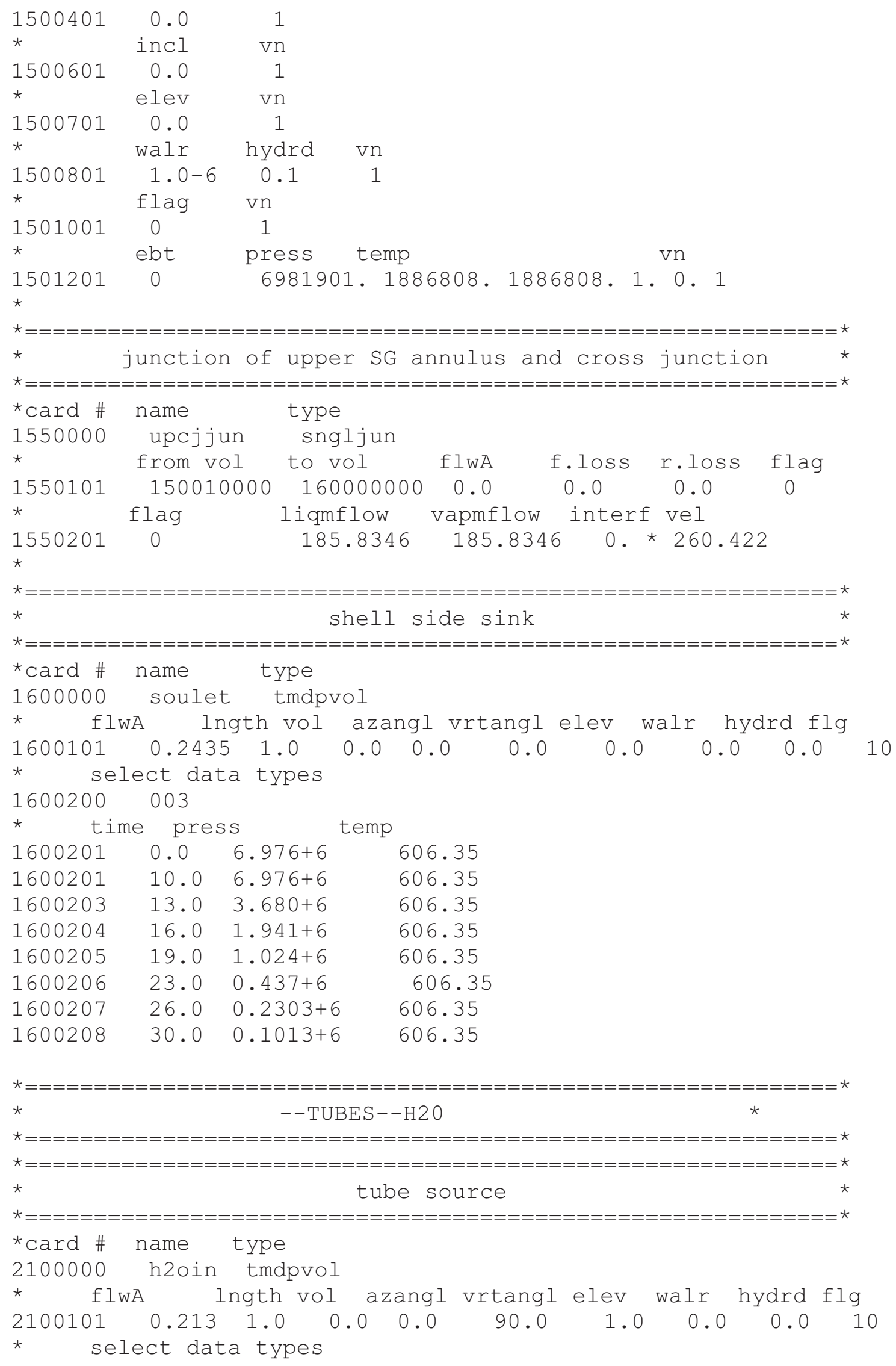




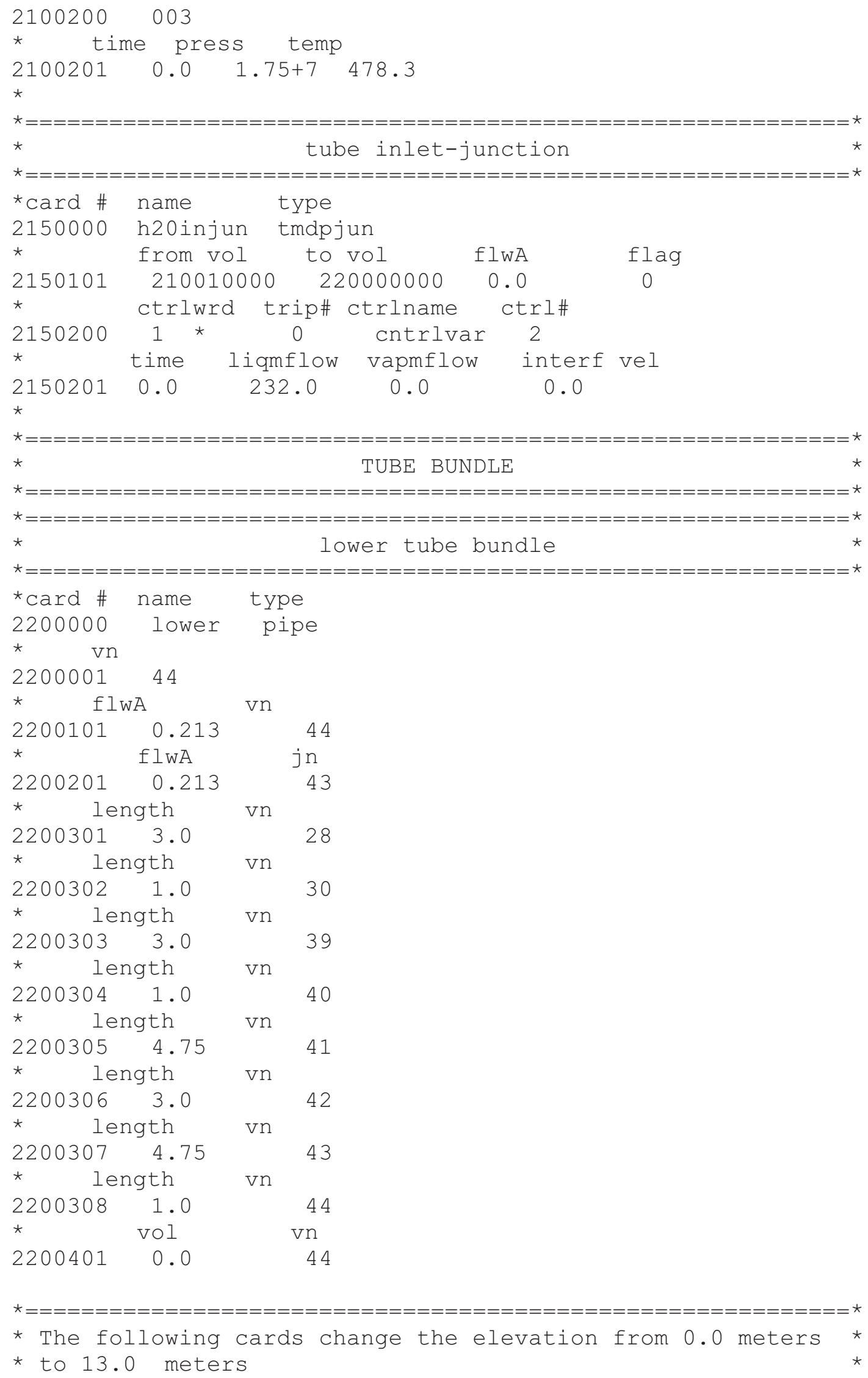




\begin{tabular}{|c|c|c|}
\hline$\star$ & incl & $\mathrm{Vn}$ \\
\hline 2200601 & 90.0 & 1 \\
\hline 夫 & incl & vn \\
\hline 2200602 & 3.18474 & 28 \\
\hline$\star$ & incl & $\mathrm{Vn}$ \\
\hline 2200603 & 90.0 & 30 \\
\hline 夫 & incl & $\mathrm{Vn}$ \\
\hline 2200604 & 3.18474 & 39 \\
\hline$\star$ & incl & vn \\
\hline 2200605 & 90.0 & 40 \\
\hline$\star$ & incl & vn \\
\hline 2200606 & 0.0 & 41 \\
\hline 夫 & incl & vn \\
\hline 2200607 & 90.0 & 42 \\
\hline 夫 & incl & $\mathrm{Vn}$ \\
\hline 2200608 & 0.0 & 44 \\
\hline$\star$ & elev & vn \\
\hline 2200701 & 3.0 & 1 \\
\hline 夫 & elev & $\mathrm{vn}$ \\
\hline 2200702 & 0.1666 & 28 \\
\hline 夫 & elev & $\mathrm{vn}$ \\
\hline 2200703 & 1.0 & 30 \\
\hline 夫 & elev & $\mathrm{vn}$ \\
\hline 2200704 & 0.1666 & 39 \\
\hline 夫 & elev & $\mathrm{Vn}$ \\
\hline 2200705 & 1.0 & 40 \\
\hline * & elev & Vn \\
\hline 2200706 & 0.0 & 41 \\
\hline$\star$ & elev & $\mathrm{vn}$ \\
\hline 2200707 & 3.0 & 42 \\
\hline * & elev & $\mathrm{Vn}$ \\
\hline 2200708 & 0.0 & 44 \\
\hline * & walr & hydrd \\
\hline $\begin{array}{l}2200801 \\
\star\end{array}$ & $1.0-6$ & 0.0248 \\
\hline \multicolumn{3}{|c|}{$\begin{array}{l}\text { * }============================================== \\
\text { * The following cards change the loss rate at the junctions * } \\
\text { * of pipes with bends. }\end{array}$} \\
\hline \multicolumn{3}{|c|}{ 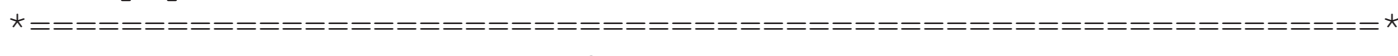 } \\
\hline * & floss & rloss jn \\
\hline 2200901 & 0.0 & 0.0 \\
\hline * & flag & $\mathrm{vn}$ \\
\hline 2201001 & 0 & 44 \\
\hline * & flag & $j n$ \\
\hline 2201101 & 0 & 43 \\
\hline * & ebt & press \\
\hline 2201201 & 0 & $17501800 \cdot 883921 \cdot 2394549 \cdot 0 \cdot 0 \cdot 1$ \\
\hline * & ebt & press temp \\
\hline $\begin{array}{l}2201202 \\
2201203\end{array}$ & 0 & $17487060 \cdot 930015 \cdot 2394981 \cdot 0 \cdot 0 \cdot 2$ \\
\hline 2201204 & 0 & 17481642.1020260 .2395138 .0 .0 .4 \\
\hline
\end{tabular}




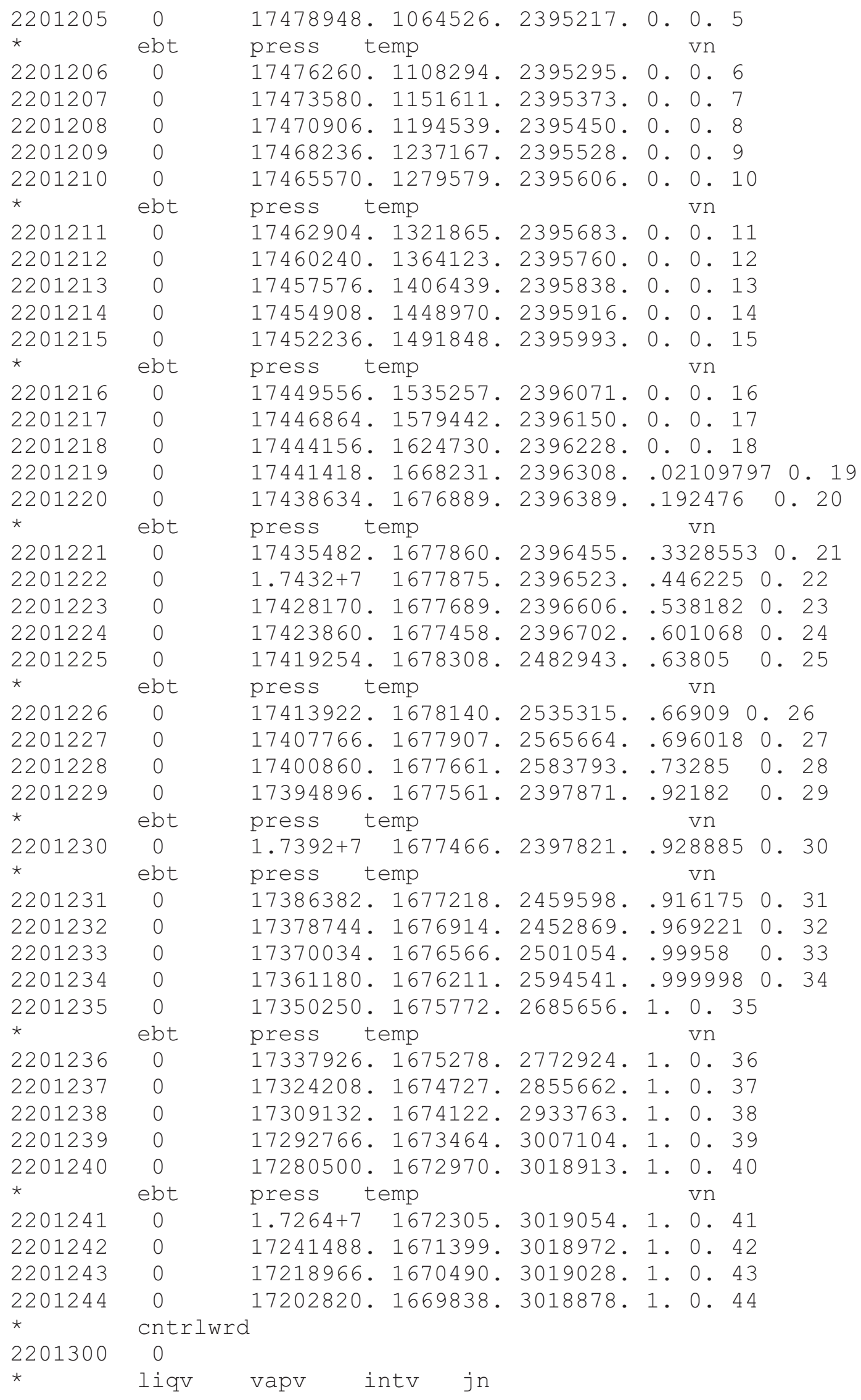




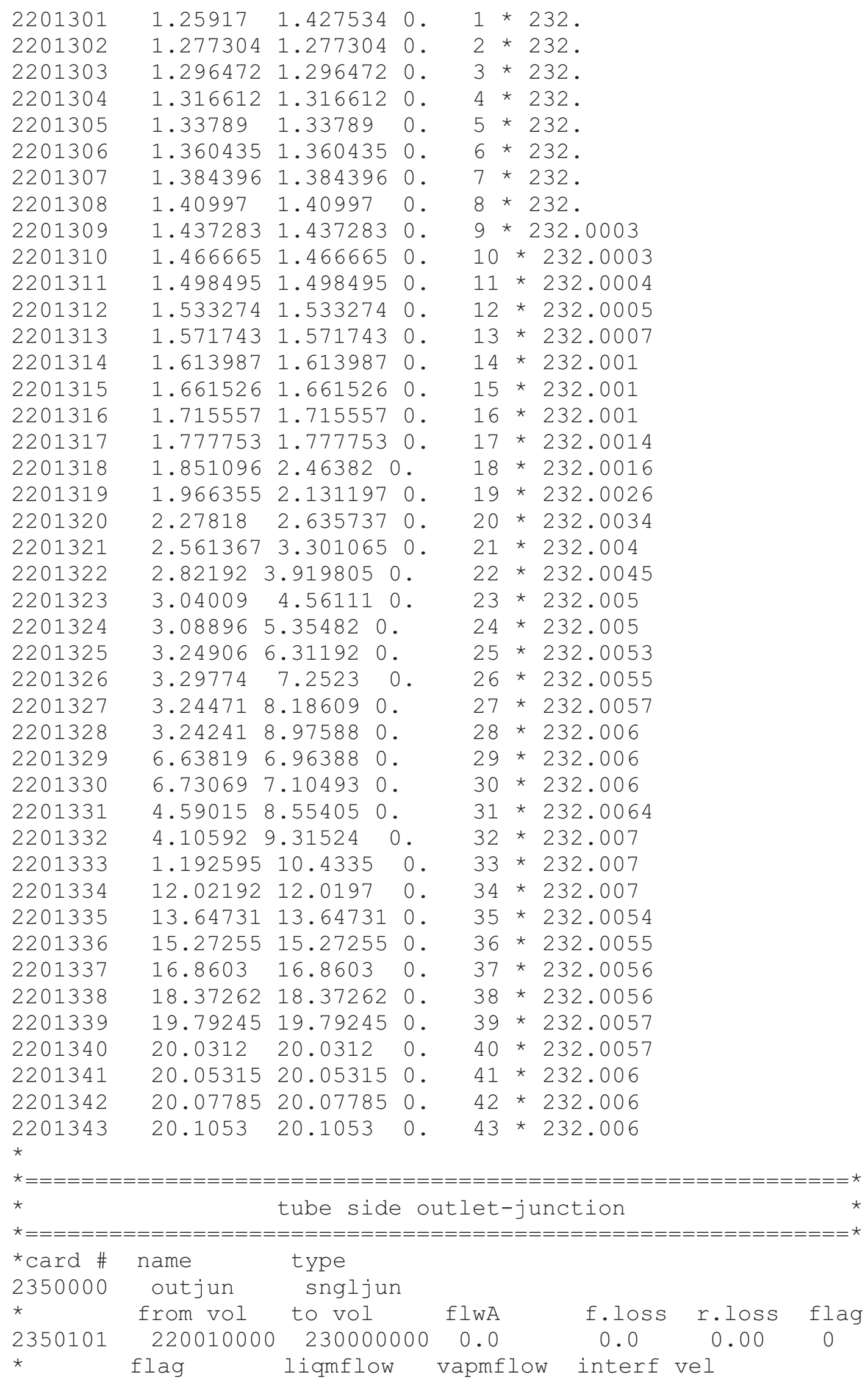




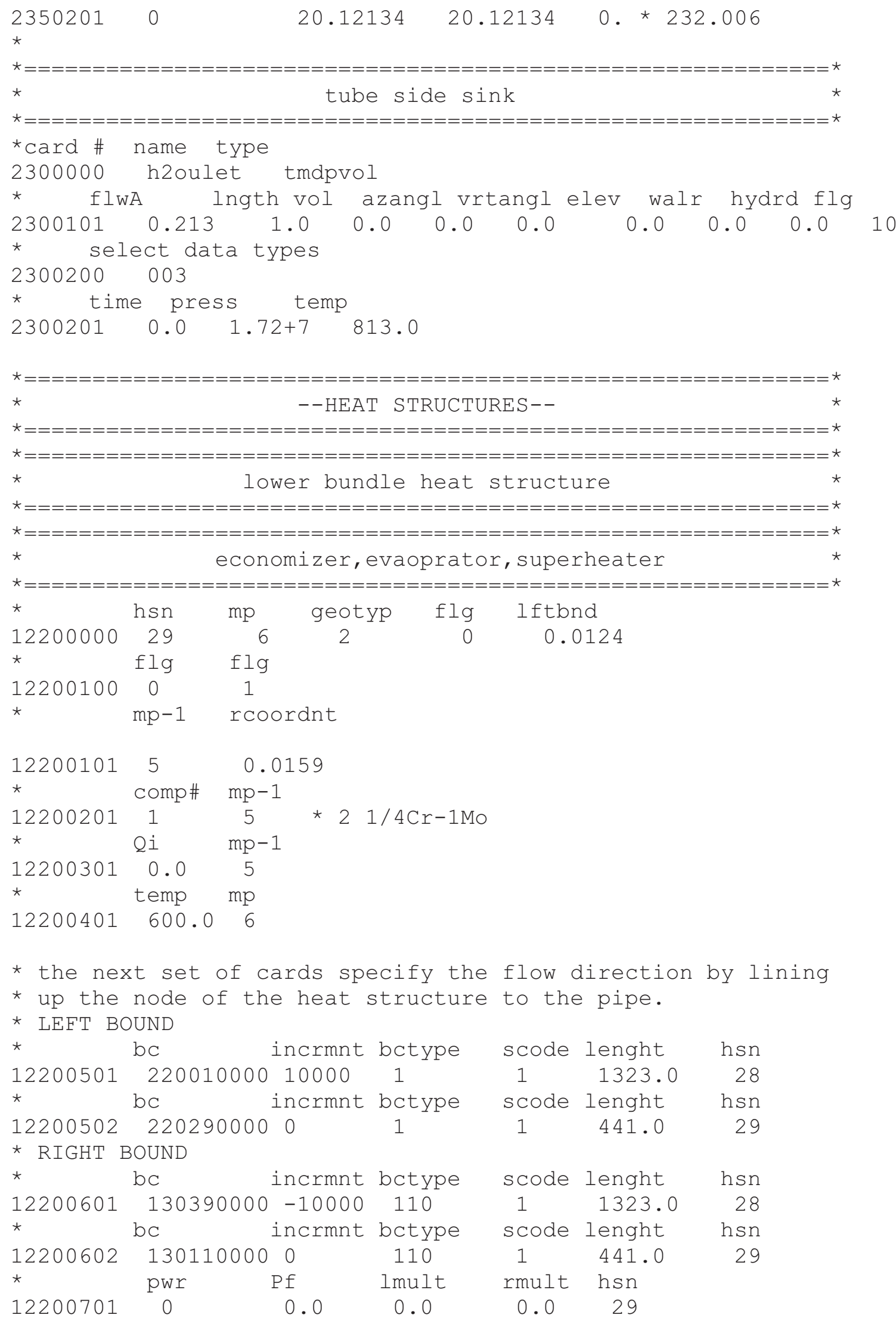




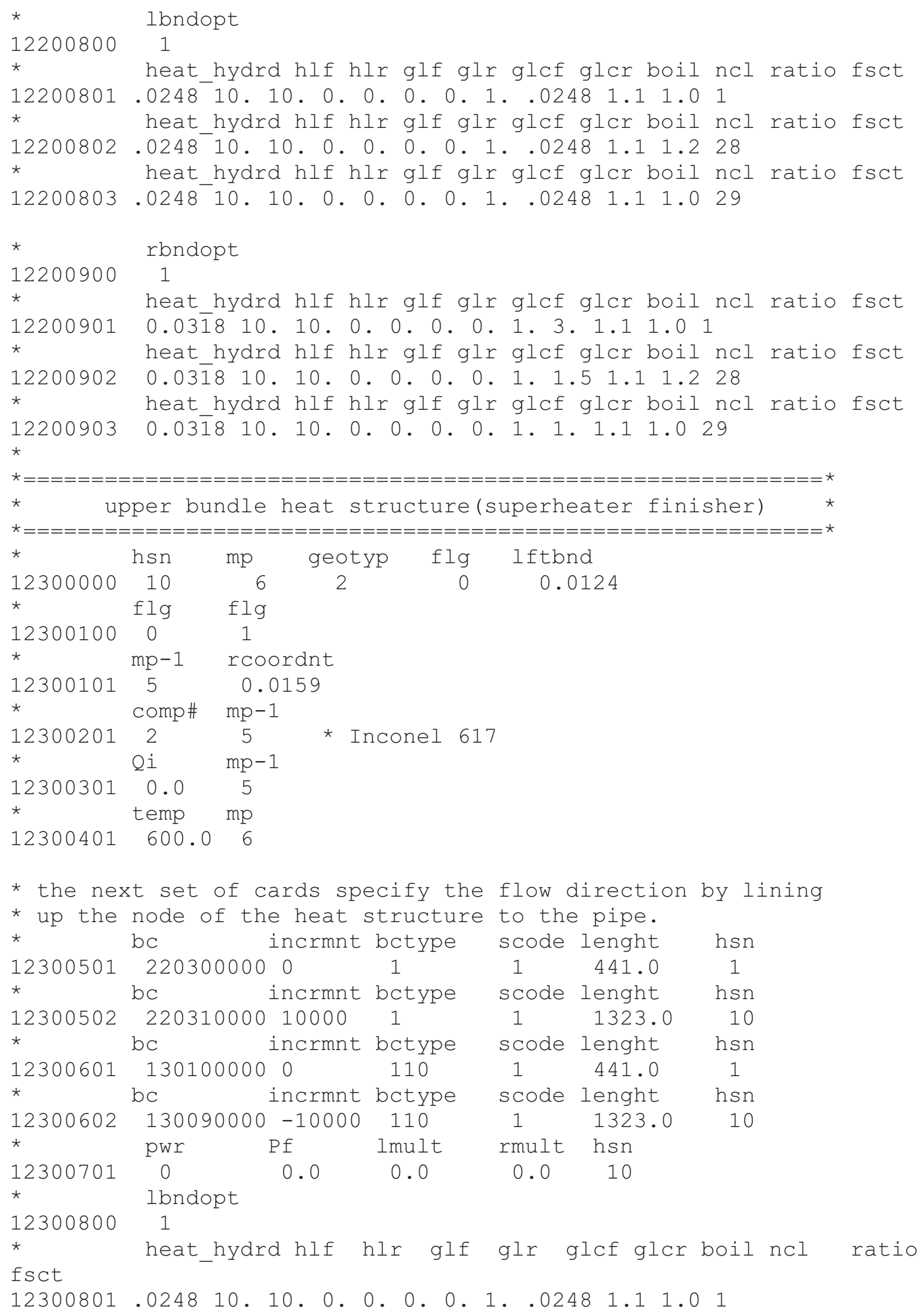




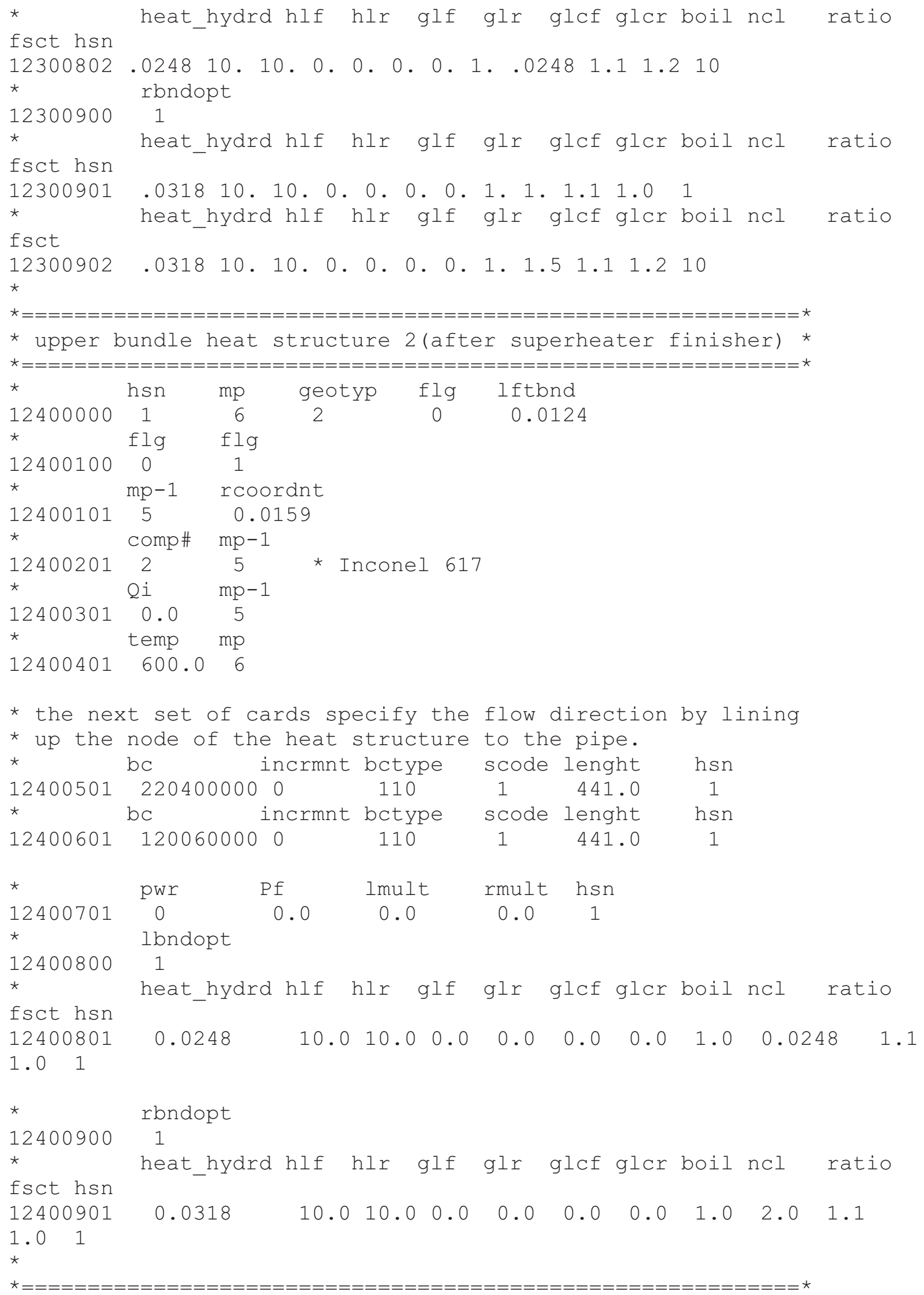




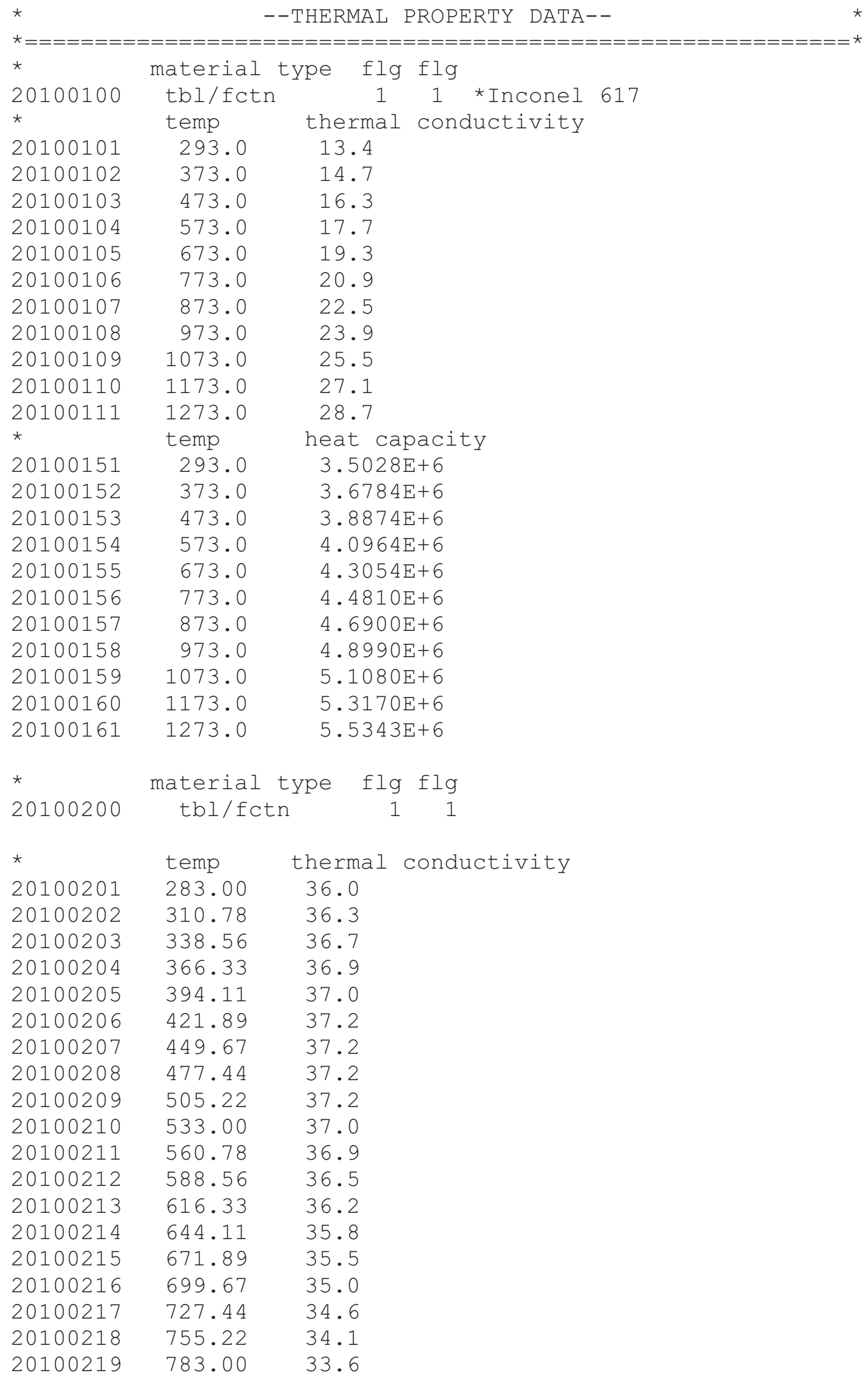




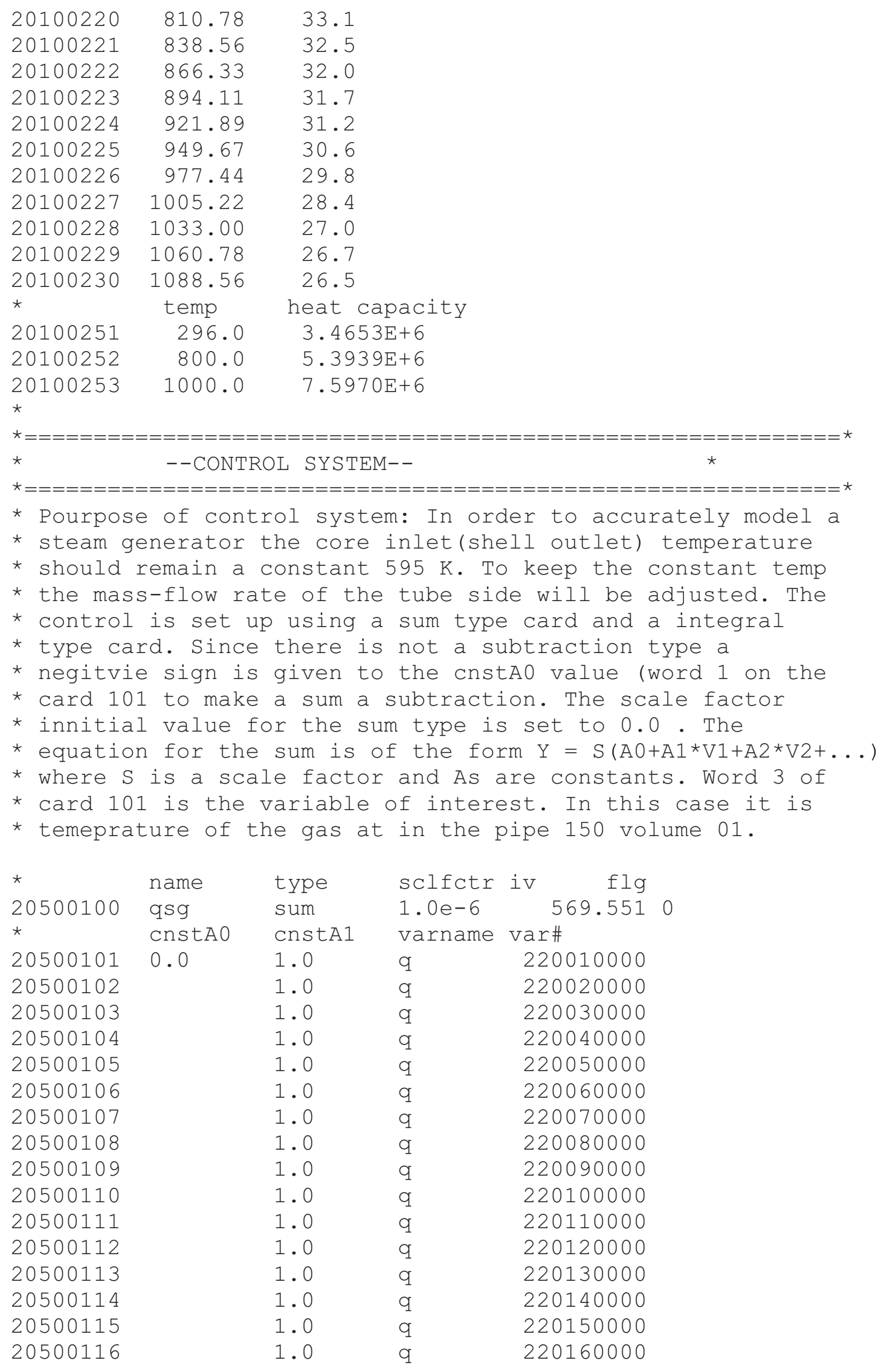




\begin{tabular}{|c|c|c|c|c|c|}
\hline 20500117 & & 1.0 & $q$ & 220170000 & \\
\hline 20500118 & & 1.0 & $q$ & 220180000 & \\
\hline 20500119 & & 1.0 & $q$ & 220190000 & \\
\hline 20500120 & & 1.0 & q & 220200000 & \\
\hline 20500121 & & 1.0 & q & 220210000 & \\
\hline 20500122 & & 1.0 & $q$ & 220220000 & \\
\hline 20500123 & & 1.0 & $q$ & 220230000 & \\
\hline 20500124 & & 1.0 & q & 220240000 & \\
\hline 20500125 & & 1.0 & $q$ & 220250000 & \\
\hline 20500126 & & 1.0 & $q$ & 220260000 & \\
\hline 20500127 & & 1.0 & $q$ & 220270000 & \\
\hline 20500128 & & 1.0 & $q$ & 220280000 & \\
\hline 20500129 & & 1.0 & $q$ & 220290000 & \\
\hline 20500130 & & 1.0 & $q$ & 220300000 & \\
\hline 20500131 & & 1.0 & $q$ & 220310000 & \\
\hline 20500132 & & 1.0 & $q$ & 220320000 & \\
\hline 20500133 & & 1.0 & $q$ & 220330000 & \\
\hline 20500134 & & 1.0 & $q$ & 220340000 & \\
\hline 20500135 & & 1.0 & q & 220350000 & \\
\hline 20500136 & & 1.0 & $q$ & 220360000 & \\
\hline 20500137 & & 1.0 & $q$ & 220370000 & \\
\hline 20500138 & & 1.0 & $q$ & 220380000 & \\
\hline 20500139 & & 1.0 & $q$ & 220390000 & \\
\hline 20500140 & & 1.0 & q & 220400000 & \\
\hline 20500141 & & 1.0 & q & 220410000 & \\
\hline 20500142 & & 1.0 & $q$ & 220420000 & \\
\hline 20500143 & & 1.0 & $q$ & 220430000 & \\
\hline 20500144 & & 1.0 & q & 220440000 & \\
\hline * & name & type & sclfctr $i$ & iv $\quad f l g$ & \\
\hline 20500200 & mult1 & mult & 1.0 & 550.1660 & \\
\hline (2) & varname & var\# $\quad \mathrm{v}$ & arname var & & \\
\hline 20500201 & voidf, 22 & 0080000 & tempf, 2200 & 080000 & \\
\hline * & name & type & sclfctr $i$ & iv $\quad f l g$ & \\
\hline 20500300 & mult2 & mult & 1.0 & 0 & \\
\hline * & varname & $\operatorname{var} \# \quad v$ & arname var & & \\
\hline 20500301 & voidg, 22 & 0080000 & tempg, 2200 & 080000 & \\
\hline$\star$ & name & type & sclfctr & iv & \\
\hline 20500400 & tempfg & sum & 1.0 & 551.1660 & \\
\hline$\star$ & cnsta 0 & cnstA1 & varname & var\# cnstA2 & varname var\# \\
\hline $\begin{array}{l}20500401 \\
\star\end{array}$ & 1.0 & 1.0 & cntrlvar & $r 2 \quad 1.0$ & cntrlvar 3 \\
\hline
\end{tabular}

- End of input. 
Appendix C

\section{Beginner's RELAP5-3D User Guide}




\section{Appendix C Beginner's RELAP5-3D User Guide}

\section{C-1. Background}

RELAP5 is based on FORTRAN77, and parts have been updated to newer versions of FORTRAN. RELAP originated as a program designed to model loss of coolant accidents (LOCAs) and other transients in nuclear power plants.

\section{C-2. The Basics of RELAP}

RELAP is coded in a text editor. Information is entered onto a card. The card is reminiscent of the ways data were literally entered into a computer on a physical data card. The card can now be thought of as a line of code. The pieces of data on a card are referred to as words. A card can only hold up to 80 characters. Words can be alphanumeric, real, or integer characters. Words act as pieces of data and can also act like a directory or a set of on or off switches that determine the meaning of the words of following cards.

\section{C-3. Simplify}

Modeling in RELAP requires simplification of the actual structures. A model is started as simply as possible. For example, a bundle of tubes in a heat exchanger can be modeled as one large tube with the same surface area, cross-sectional area, hydraulic diameter, and heated hydraulic diameter as the tube bundle.

\section{C-4. Required/Optional entries}

It is important to understand which cards are required for the code to run and which are optional. In the same way, it is vital to know when optional cars should be used and when they can be left out.

\section{C-5. What Every User Should Know}

- Don’t use tabs.

- Use lower caps while coding. Comment can be capitalized.

- Break up sections and give them descriptive titles.

- Comment everything, including each word of a card. These comments will serve as a reminder during debugging.

- If using a fluid other than $\mathrm{H}_{2} \mathrm{O}$, enter NEWATH for card 100. This adds a new module which allows for the use of other fluids.

- Before the code, write a brief description of the purpose of the code and the parameters used so that others may use the code with ease.

- Before the code, state the assumptions that have been made about the model.

- Asterisk (*) or a dollar symbol (\$) is used to indicate comments.

- $0 * * * * * * * * * *$ in the ."p" file shows where errors have occurred. 
- Area, length and volume are input parameters for all types of volumes. Only two of the three parameters need to be entered. The third value will be calculated and should be left blank to avoid errors.

- Make sure units match the input units.

- The number of junctions is always one less that the number of volumes.

- A single heat structure can be linked to multiple hydrodynamic volumes.

- The sign of the elevation must match the sign of the inclination.

- Spiral pipes can be modeled by unraveling the spiral, making a long tube that is slightly angled above horizontal but ends up at the same elevation as the spiral tube originally reached.

- Phase changes depend on temperature and pressure and do not need to be specified in the model.

- Be careful of inputs. Some only alter the geometry and are not accounted for in the calculations.

- If words of a card are missing, RELAP automatically looks to the next card to find the missing values. If these values do not correspond in type and number, RELAP will give an error. Also, if the words of one card are too long, they can be placed on the next card of the same type.

\section{C-6. Hydrodynamic structures}

In RELAP5, the azimuthal or horizontal angle is only used for visualization purposes and not in calculations. Positive angles are a rotation from the $\mathrm{x}$ to the $\mathrm{y}$ axis and can have value from 0 to 360 degrees.

The inclination or vertical angle is used in determining which flow regime will be used. RELAP considers a component that has an angle of 30 degrees or less from horizontal and will use the horizontal flow regime. If the angle is 60 degrees or more, the vertical flow regime is used. RELAP will interpolate between 30 and 60 degrees. In order to have an elevation change, a component must have an inclination angle; otherwise, an error will result.

An annulus must be vertical; otherwise, use a pipe with the same flow area.

\section{C-6.1 Hydrodynamic Components and Their Input Name}

\section{Component}

\begin{tabular}{ll}
\hline Single volume & snglvol \\
Time-dependent volume & tmdpvol \\
Single Junction & sngljun \\
Time-dependent junction & tmdpjun \\
Branch & branch \\
Separator & separatr \\
Pipe & pipe \\
Annulus & annulus \\
Pressurizer & prizer \\
Feedwater heater & fwhtr \\
Jetmixer & jetmixer \\
Turbine & turbine \\
EEC mixer & eccmix \\
Valve & valve
\end{tabular}




$\begin{array}{ll}\text { Pump } & \text { pump } \\ \text { Multiple junction } & \text { mtpljun } \\ \text { Accumulater } & \text { accum } \\ \text { Multi-dimensional component } & \text { multid }\end{array}$

\section{C-6.2 Time-Dependent Volume Component}

The time-dependent volume is used to initialize pressure and temperature in the model. The timedependent volume usually serves as a source or inlet for the model. Temperature and pressure can be varied with time. This is one way of modeling transients. The volume flow area should be the same as the next hydrodynamic component.

\section{C-6.3 Time-Dependent Junction Component}

The time-dependent junction sets the initial mass-flow for the system and can also be used in the modeling of transients. Generally, a time-dependent volume is followed by a time-dependent junction.

\section{C-6.4 Heated Perimeter/Diameter}

$$
\begin{aligned}
& D_{\text {Heated Hydraulic }}=\frac{4 * A_{c}}{P_{\text {Heated }}} \\
& D_{\text {Hydraulic }}=\frac{4 * A_{c}}{P_{\text {Hydraulic }}} \\
& P_{\text {Heated }}=2 * \pi * r_{\text {Heated }} \\
& P_{\text {Hydraulic }}=2 * \pi * r_{\text {Hydraulic }}
\end{aligned}
$$

\section{C-6.5 Thermal Property Data}

- Table data must be given in increasing order

- Temperature must be given in $\mathrm{K}$ or ${ }^{\circ} \mathrm{F}$

- Thermal conductivity units are $\mathrm{W} / \mathrm{m} * \mathrm{~K}$ or $\mathrm{Btu} / \mathrm{s} * \mathrm{ft} *{ }^{\circ} \mathrm{F}$

\section{C-6.6 Flags}

Flags are used to control options for card inputs, correlations, models, and so on. Inputs for a flag consist of several integers. Each integer corresponds to a particular option. Integer options and meaning can be found in Appendix A, RELAP5-3D Input Data Requirements manual. It is important to understand that REALP reads the flag integers from right to left or back to front. This allows the modeler to enter in fewer numbers as flags can contain upwards of seven integers.

\section{C-6.7 Major/Minor Edits}

Major edits are like taking a snap shot of all model parameters. The frequency of the edits can be specified using Card 201. The major edits are used in generating data for plots. When running an input deck to verify that the code works and gives results, the major edits can be infrequent so that run time is minimized. If detailed plots need to be generated from a transient run, major edits should be taken often 
depending on how long the code is actually running. Short transients require frequent major edits while long transients may not need as frequent edits for data resolution.

Minor edits specify individual parameters to be taken at the specified interval. Minor edits are useful if only one parameter or a parameter that is not on the major edits or needs to be taken often, but no other parameters are required. 